Published in final edited form as:

Nat Rev Neurosci. 2019 June ; 20(6): 330-345. doi:10.1038/s41583-019-0140-6.

\title{
Novel electrode technologies for neural recordings
}

\author{
Guosong Hong ${ }^{1,2,3}$ and Charles M. Lieber ${ }^{1,4,}{ }^{*}$ \\ ${ }^{1}$ Department of Chemistry and Chemical Biology, Harvard University, Cambridge, Massachusetts, \\ USA \\ ${ }^{2}$ Department of Materials Science and Engineering, Stanford University, Stanford, California, USA \\ ${ }^{3}$ Stanford Neurosciences Institute, Stanford University, Stanford, California, USA \\ ${ }^{4}$ John A. Paulson School of Engineering and Applied Sciences, Harvard University, Cambridge, \\ Massachusetts, USA
}

\section{Abstract}

\begin{abstract}
Neural recording electrode technologies have contributed considerably to neuroscience by enabling the extracellular detection of low-frequency local field potential oscillations and highfrequency action potentials of single units. Nevertheless, several long-standing limitations exist, including low multiplexity, deleterious chronic immune responses and long-term recording instability. Driven by initiatives encouraging the generation of novel neurotechnologies and the maturation of technologies to fabricate high-density electronics, novel electrode technologies are emerging. Here, we provide an overview of recently developed neural recording electrode technologies with high spatial integration, long-term stability and multiple functionalities. We describe how these emergent neurotechnologies can approach the ultimate goal of illuminating chronic brain activity with minimal disruption of the neural environment, thereby providing unprecedented opportunities for neuroscience research in the future.
\end{abstract}

\section{Introduction}

In the nervous system, massive numbers of neurons constantly generate and transmit electrophysiological signals to communicate between neurons and brain regions. The electrical nature of neurophysiology was first revealed by Italian scientist Luigi Galvani more than two centuries ago using the primitive electrode technologies of his age ${ }^{1}$. In the following two centuries, several generations of neurophysiologists, including von Helmholtz ${ }^{2}$, Erlanger, Gasser ${ }^{3}$, Hodgkin and Huxley ${ }^{4}$, have made their independent contributions to the understanding of the nervous system. By developing their own recording electrodes, these founding fathers of neurobiology all succeeded in detecting neural activity

\footnotetext{
*cml@cmliris.harvard.edu.

Author contributions

Both authors researched data for article, made substantial contributions to discussion of the content, wrote the article and reviewed or edited the manuscript before submission.

Competing interests

The authors declare competing interests as defined by Nature Research as they are listed as co-inventors on patents filed by Harvard University.
} 
from relatively large dissected nerves and axons - for example, the $0.5-1 \mathrm{~mm}$-wide giant squid axons studied by Hodgkin and Huxley ${ }^{4}$. In 1957, Hubei took an important step forward by fabricating sharpened tungsten electrodes with sub-micron-diameter tip sizes, thereby recording from the much smaller neurons and axons in the mammalian brain, as demonstrated with the recording of extracellular action potentials from the cat brain 5 . Hubei's invention has had far-reaching impact in both neuroscience and neuroengineering. These electrodes enabled seminal contributions to visual neurophysiology with Wiesel ${ }^{6}$, and ushered in the development of newer probes, ranging from tetrodes $[\mathrm{G}]^{7}$ to microfabricated silicon Michigan-type microelectrode arrays $[\mathrm{G}]^{8}$ and Utah-type microelectrode arrays $[\mathrm{G}]^{9}$ (MEAs; Fig. 1).

The broadband neural signals recorded from the extracellular space by either penetrating depth electrodes or surface electrodes can be processed to extract signals in different frequency bands, enabling the detection of at least two different types of voltage signals, the slow-varying local field potentials [G] (LFPs), which reflect collective transmembrane currents from multiple neurons, and action potentials lasting in the order of milliseconds ('spikes') from individual neuron or single-units ${ }^{10}$. LFPs and single-unit action potentials are generally present in the raw recording traces in the time domain, which can be decomposed by Fourier transform [G] into component frequency bands as a spectrogram $[\mathrm{G}]^{10}$. As LFPs and single-unit action potentials occupy distinct frequency bands in the spectrogram (typically $<100 \mathrm{~Hz}$ for LFPs and $>250 \mathrm{~Hz}$ for single-unit action potentials), they can be separated by applying analogue or digital filters to selectively pass signals in lower- and higher-frequency bands, respectively ${ }^{10}$.

LFPs have a critical role in coordinating the activity of different regions of the brain, and synchronizing the activity of individual neurons with that of a neural network, through phase locking to the global rhythm ${ }^{10}$. For example, theta-frequency $(4-8 \mathrm{~Hz})$ oscillations and phase-locked discharge of neurons to theta waves are found in the hippocampus and some cortical areas, providing potential mechanisms to synchronize neuronal assemblies involved in complex processes and functions of the brain such as memory formation and neuroplasticity ${ }^{11}$.

Individual neurons represent the structural and functional units of the nervous system, with their spatiotemporally resolved activities holding the key to understanding the inner workings of the brain ${ }^{12,13}$. Therefore, as the cornerstone of in vivo electrophysiology, this Review focuses on recording of single-unit spiking activity from individual neurons. Singleunit spikes are filtered from neural signals in the high-frequency spectrum $(>250 \mathrm{~Hz})$. Importantly, extracellular electrodes provide information distinct from that of intracellular patch-clamp recordings from single neurons ${ }^{14}$ : extracellular electrodes can record spiking from multiple nearby neurons (usually within a distance of $\sim 140 \mu \mathrm{m}$ ) ${ }^{15}$. When there is minimal overlap of signals from multiple neurons in the time trace, spikes recorded at the same electrode can be temporally resolved and assigned to individual neurons ${ }^{16}$; by contrast, when spiking activity from multiple neurons cannot be resolved for assignment to individual neurons, it is usually referred to as multi-unit activity (MUA) ${ }^{17-19}$. 
The seemingly complicated matter of identifying each firing neuron is usually addressed by taking into account the difference between the relatively short duration of spikes and the longer interspike intervals (which reduces or eliminates signal overlap), and the distance dependence of recorded spike amplitudes ${ }^{20}$. In addition, oversampling recording electrodes such as tetrodes ${ }^{21}$ and high-density Michigan-type silicon probes ${ }^{16}$ further facilitate spike separation and assignment to individual neurons. Thus, single-unit signals generated by different neurons can be temporally resolved and, based on the distinct amplitudes and waveforms of action potentials, the identity of each putative neuron discerned (Fig. 2a) ${ }^{16}$.

Conventional electrode technologies used since the invention of tungsten wire electrodes (Fig. 1) $)^{22-29}$ have made prominent contributions to neuroscience. However, they are not fundamentally different from the primitive electrodes used by Galvani more than two centuries ago: they use a limited number of electrodes, establish a non-biological interface between rigid electrode materials and soft neural tissue and are limited in their ability to simultaneously interrogate and modulate neural activities. Moreover, conventional neural recording electrode technologies now compete with other neurotechnologies — particularly calcium and voltage imaging using genetically encoded indicators ${ }^{30}$, and functional MRI (fMRI) of large-scale collective neural activities via neurovascular coupling ${ }^{31}$. Calcium- and voltage-imaging techniques can record the activity of hundreds to thousands of neurons simultaneously over millimeter square areas ${ }^{32}$ and fMRI can interrogate brain activity from the same subject over long temporal spans. These developments urge new breakthroughs in electrode technologies for neural recordings with greater spatiotemporal span, higher resolution and multiplexed functionality (Fig. 2b).

In this Review, we discuss advances in neural recording electrode technologies aimed at stable long-term recordings of single-neuron activity with high spatial integration, and multifunctional interrogation of the interfaced neural tissue. We focus on how conventional neurotechnologies have been surpassed by many orders of magnitude in space and time, and how the latest advances point to future development of neural probes. Other emergent neurotechnologies, such as genetically encoded calcium or voltage indicators and optogenetic control of neural activity, are reviewed elsewhere ${ }^{32-34}$ and are not discussed here. Nonetheless, we offer insight on the potential to combine electrode technologies with optical methods for future neuroscience studies by discussing the strengths and limitations of electrode and optical techniques.

\section{Encouraging novel technologies}

The past decade has witnessed the emergence of several novel electrode technologies that enable more precise, more detailed and longer-term recordings of the activity of neuronal populations (Fig. 1). The development of these technologies has been driven by several factors, including national and international research initiatives, the maturation of fabrication technologies in silicon-based electronics industry and the long-standing challenge of chronic immune response evoked by conventional electrodes.

First, since the announcement of the National Institutes of Health (NIH) Brain Research through Advancing Innovative Neurotechnologies (BRAIN) initiative in the $\mathrm{US}^{35}$, the past 5 
years have seen the emergence of several other brain research initiatives and consortia, such as the US Defense Advanced Research Projects Agency (DARPA) Neural Engineering System Design (NESD) programme in the US, the Human Brain Project (HBP) in Europe, the Brain/MINDS (Brain Mapping by Integrated Neurotechnologies for Disease Studies) project in Japan and the China Brain Project ${ }^{36}$. These programmes called for a quantum leap in available neurotechnologies, especially in light of the spatial-temporal dilemma: the discrepancy between the spatial and temporal resolution as well as temporal spans of interrogation of available neurotechnologies and the spatial and temporal scales of relevant brain processes. Important brain processes occur over months to years in multiple coordinated brain regions, but involve electrophysiological changes that must be quantified on the millisecond and micrometer scales of individual neurons. Conventional neurotechnologies cannot keep up with the high resolutions and large spans of these desired spatiotemporal scales, in which each neurotechnology has its own strengths and limitations in studying specific aspects of the brain ${ }^{37}$.

As a second incentive, maturation of fabrication and integration technologies in siliconbased electronics, as well as advances in nanoscience and unconventional electronics, have converged with these growing demands of neuroscience. In the semiconductor industry, Moore's Law summarized that the number of transistors [G] in integrated circuits approximately doubles about every 2 years, a trend that started in the early 1970s and remains nearly valid today ${ }^{38}$. Similarly, the number of recorded single neurons also follows a trend of exponential growth, albeit with slower pace than that outlined by Moore's Law, instead approximately doubling every 7 years ${ }^{39}$. To keep pace, development of novel electrode technologies for neural recording can take advantage of research-and-development fabrication lines from the semiconductor industry, which may not be state-of-the-art but nevertheless have potential for integrating far beyond current neurotechnologies (Box 1). Notably, although such advanced fabrication may contribute to increased device density, Moore's Law cannot be directly translated to neural recording unless fundamental changes are made in the types of devices used in probes. This intrinsic limitation is due to unfavorable scaling of electrode impedance $[\mathrm{G}]$ and noise with reduced electrode sizes (Box 1 ) as well as challenges in parallel interfacing of multiplexed inputs and outputs (I/O) with increasing number of channels [G]. The ability to simultaneously record a larger number of neurons with multi-channel recording electrodes also allows analysis of the temporal coherence of spikes across channels, enabling accurate sorting and assignment of spikes to individual neurons ${ }^{16,21}$.

A third and growing focus of novel electrode technology development has been to address the long-standing challenge of chronic immune response and relative shear motion at the probe-tissue interface that is attributed to the mechanical mismatch between the probe materials and the neural tissue (Box 2) ${ }^{40,41}$. The chronic immune response, shear motion of implanted probes, chemical instability of electrodes, delamination and degradation of insulating layers, as well as potential infection through percutaneous leads, all lead to unstable neural recording interfaces over time. Yet, neural circuits and networks within the brain naturally evolve across time scales over which probes are unstable, constraining information that can be obtained in neuroscience studies. Addressing this challenge calls for probes that do not affect the studied system and that do not affect the endogenous 
distribution, density and connectivity of neurons and glia, the latter of which are also key to neural circuit development and maintaining normal brain function (Box $)^{42,43}$.

The three factors above have converged to encourage the development of technologies that, will enable, among other things, high spatial integration (to record a large number of neurons simultaneously), long-term recording stability at the single-neuron level and multifunctional integration, to enable electrical, optical, and/or and biological modulation of recorded activity. These directions are yielding neural probes with their own strengths and limitations, while opening up potential opportunities for neuroscience.

\section{Spatial integration}

Understanding the coordinated activity underlying brain functions requires a substantial increase in the number of single neurons that can be monitored simultaneously. In turn, this necessitates large arrays of multiplexed recording sites in the same neural probe, with minimal footprint. Although the increase in the number of neurons that can be simultaneously recorded has been slower than that estimated by Moore's Law (Box 1), adaptation of well-established semiconductor industry fabrication capabilities has enabled recording electrodes to be reduced in size and the integration of electrodes with higher density, to afford unprecedented spatial resolution and multiplexity [G].

\section{Advances in electrode technologies with high spatial integration}

Among conventional neural recording electrode platforms, the planar distribution and monolithic integration of multiple recording sites into a Michigan-type silicon probe can be readily scaled up in number and density using fabrication technology of the semiconductor industry. Latest advances in complementary metal-oxide-semiconductor [G] (CMOS) technology has enabled incorporation of recording electrodes with integrated multiplexing circuits in the same silicon probe shaft, resulting in more compact I/O connections at the probe base ${ }^{44-48}$. Therefore, it is not surprising to see advances in design and fabrication of large-scale neural recording electrodes that build on CMOS-based Michigan-type silicon probes, including 'Neuropixels ${ }^{49}$, 'NeuroSeeker' ${ }^{50}$, and 3D silicon probes ${ }^{51}$.

The Neuropixels probe features 960 recording electrodes, each measuring $12 \mu \mathrm{m} \chi 12 \mu \mathrm{m}$ and spaced (centre-to-centre) by $25 \mu \mathrm{m}$, fabricated with a custom $130 \mathrm{~nm}$ CMOS process on a single, $10 \mathrm{~mm}$-long and $70 \mu \mathrm{m}$-wide shank. The probe can be programmed to actively switch between and address the electrodes via 384 independent recording channels (Fig. 3a; Table 1). Using two Neuropixels probes directly inserted into different sites of the same brain, >700 neurons were recorded simultaneously from five brain regions in an awake but restrained mouse. Neuropixels was also used to probe functionally connected brain regions involved in spatial navigation in freely moving rats ${ }^{49}$. In a more recent study, eight Neuropixels probes were implanted into the same mouse brain to provide large-scale mapping of activity in the forebrain region in conjunction with calcium imaging in the visual cortex. Some preliminary work has taken advantage of high-throughput recordings in superficial cortical regions using calcium imaging, and in the depth dimension using Neuropixels probes, to reveal high-dimensional correlations between spontaneous orofacial behaviours and brain-wide neural activity in mice ${ }^{52}$. 
NeuroSeeker probes were also fabricated with the $130 \mathrm{~nm}$ CMOS technology and achieved simultaneous recordings from 1344 electrodes, offering the greatest number of independent recording sites per probe to date ${ }^{50}$. The single shank of the NeuroSeeker probe inserted into targeted brain regions allowed for simultaneous recordings of LFPs and single-unit action potentials from the somatosensory cortex, hippocampus and thalamus. NeuroSeeker and similar high-density CMOS-based active neural probes ${ }^{46,48,53}$ incorporate multiplexing electronics in the probe shank. This multiplexing circuitry requires power and leads to heat dissipation in the brain tissue, and thus represents a constraint that can limit further increases in electrode numbers using this strategy ${ }^{54}$. Moving all active electronic elements off the implanted portion of the probe solves this problem but correspondingly increases the size of the probe base and the headstage of the implant.

Despite the large number of independently addressable recording sites in the depth dimension of the probe, the fact that Neuropixels and NeuroSeeker are based on a Michigantype design means that they have difficulty with large-scale mapping along lateral dimensions (Box 1). Combining the strengths and design features of both Michigan-type and Utah-type silicon probes, 3D silicon-probe arrays have been generated by grouping 1664 channel Michigan-type probes, each of which was fabricated with standard CMOS technology, into a 3D $4 \chi 4 \chi 64$ electrode array. The 3D silicon-probe array (Table 1) enabled sampling neural activities from a volume that is $16 \chi$ larger than with a single shank silicon probe ${ }^{51}$. One specific advantage of the $3 \mathrm{D}$ silicon-probe array is that the heatgenerating, active multiplexing electronics are placed outside the skull, minimizing heat dissipation in the brain tissue ${ }^{51,54}$. Although each shank of the 3D silicon-probe array has fewer recording sites (64) than the Neuropixels (960) and NeuroSeeker probes (1344), a similar strategy in which multiple Neuropixels or NeuroSeeker probes are combined into a 3D architecture with reduced base size may be promising. A similar 3D strategy was used in a recent report where four 16-channel polyimide electrode arrays were assembled into one 64-channel module, and sixteen of these modules were stacked into a 1024-channel recording system for large-scale, multi-site mapping of brain activity (Table 1) ${ }^{55}$.

Recording deep-brain neural activity with these penetrating silicon probes comes with its own shortcomings, the most prominent of which is its invasiveness ${ }^{41,56}$. Alternative advanced probe developments, which mitigate the invasiveness of penetrating electrodes at a cost of being most sensitive to surface brain layers, have focused on using flexible planar subdural ME As. For example, a flexible, 360-channel MEA was fabricated by a combination of photolithography-mediated patterned deposition of metal electrodes and interconnects and transfer printing of silicon nanoribbon transistors, on a flexible polyimide substrate $^{57}$. The flexible MEA coated a $10 \mathrm{~mm} \times 9 \mathrm{~mm}$ area of cat cortex and was used to map cortical activity during sleep, visual stimulation and epileptic seizures in feline models (Table 1) ${ }^{57}$. The relatively large $300 \mu \mathrm{m} \chi 300 \mu \mathrm{m}$ electrodes precluded the recording of single-unit action potentials from individual neurons, but the distribution of 360 electrodes in a grid enabled mapping of cortical activity patterns in the form of plane waves and spiral waves. The electrode size was subsequently reduced (to $10 \mu \mathrm{m} \chi 10 \mu \mathrm{m}$ ) to approach that of neuron soma (which measure 10-20 $\mu \mathrm{m}$ in diameter) in the NeuroGrid array, which is an electrocorticography (ECoG) array with microelectrodes fabricated by photolithography on flexible parylene substrates. The NeuroGrid array was placed on the cortical surface, 
enabling detection of LFPs and single-unit action potentials from superficial cortical neurons (Fig. 3a; Table 1) $)^{58}$.

\section{Neuroscientific importance and further development}

The high multiplexity of Neuropixels probes has allowed simultaneous recording of $>2,000$ neurons in multiple cortical areas and deeper brain structures ${ }^{49,52}$. Large-scale recordings from coordinated areas spanning much of the brain provide new opportunities for investigating the underlying mechanisms of spontaneous cortical activity patterns — for example, estimating the dimensionality of neural population activity ${ }^{59}$. In addition, silicon MEA probes enable acute recordings to be obtained immediately after brain implantation ${ }^{60,61}$. Moreover, non-penetrating subdural electrode arrays such as the NeuroGrid provide large-scale and spatially continuous recording on the cortical surface, thus allowing for identification of the anatomical locations of ripple [G]-generating cortical areas involved in hippocampus-neocortex communications with high spatial resolution ${ }^{62}$. Combining both Neuropixels- and NeuroGrid-type probes could enable simultaneous largescale recordings from subcortical and cortical regions and thereby might reveal new insights into the communication dynamics in complex brain networks ${ }^{63}$ as well as the transfer of memory traces and consolidation of memory during and after learning ${ }^{64}$.

Despite the unprecedented datasets of neural recordings generated by these large-scale electrode technologies ${ }^{54}$, the existing high-density MEA probes are not without limitations. First, it would be useful to expand the sampling volume and increase simultaneously recorded neuron count without causing greater tissue damage. The parallel combination of Neuropixels-type probes into a Utah-type array can extend the sampling volume laterally ${ }^{51}$, although remains limited by the intrinsic tissue damage caused by such rigid probes. Second, as increasing the number of electrodes generally increases probe size and the dissipation of heat from active multiplexing electronics, I/O interfaces need to be optimized in terms of accessibility to multiplexed, external recording instruments, bandwidth and weight. These factors are of particular importance for recording from freely behaving animals ${ }^{65}$. Third, the photovoltaic effect $[\mathrm{G}]$ of semiconductor devices in CMOS circuits will complicate the combination of electrophysiological recordings with optogenetic stimulation, and will require optoelectronic design with minimal crosstalk ${ }^{66}$. Fourth, further reduction of electrode sizes to afford a higher sampling resolution requires consideration of different detector technologies to address the unfavourable scaling of signal-to-noise ratio (SNR) with size (Box 1). Novel electrode technologies such as active field-effect transistors [G] (FETs) are promising candidates, as they can be scaled in size to the subcellular regime without loss of measurement bandwidth and sensitivity ${ }^{67-74}$. Fifth, despite the ease of placing flexible NeuroGrid-type arrays on the cortical surface, they compete directly in several ways with calcium or voltage imaging, which can map the activity of thousands of neurons simultaneously ${ }^{30,32}$. Compared with electrode recordings, major weaknesses of optical electrophysiology include limited penetration depth (owing to photon scattering in the brain tissue $)^{75}$, and the slow kinetics of calcium transients, which prevent direct, temporally precise recording of action potentials ${ }^{30}$. Nonetheless, the potential of depth extension with multi-photon microscopy ${ }^{76}$ and adaptive optics ${ }^{33}$, in combination with fast voltage imaging, may overtake that of non-penetrating brain probes, although the latter may prove most useful 
in freely behaving animals without head fixation. Therefore, we suggest that a focus on integrating Neuropixels-type (high-density, deep-penetration) electrodes with advances in all-optical electrophysiology ${ }^{77}$ could yield the most unique information that addresses network-level connectivity of different brain regions from the single-cell level ${ }^{63}$. Last, the latest developments of electrode technologies with high spatial integration usually do not substantially improve the issue of chronic instabilities of recordings using rigid probe designs, thus limiting their performance for long-term recordings relevant to circuit plasticity and other changes over longer time periods (Table 1). Nonetheless, it is noteworthy that the 1024-channel polyimide electrode arrays have recently demonstrated single-unit recording with ca. $50 \%$ showing a longevity for up to 283 days, as well as tracking of approximately $30 \%$ and then $20 \%$ of the same putative neurons at 5 and 10 days, respectively ${ }^{55}$.

\section{Stable long-term recording}

The brain is a dynamic system that exhibits constant changes in neuronal activity and connectivity at multiple temporal scales, ranging from the millisecond duration of singleunit action potentials to months and years for circuit-level modifications during learning and longterm memory formation ${ }^{78}$. Understanding the time-dependent progression of key cognitive processes and brain functions from the single-neuron level with implanted probe technologies thus requires a considerable increase in duration of stable neural recording. In short, one seeks to develop novel probe technology with a chronically stable neural interface as well as minimal perturbation to the endogenous distribution and density of neurons and non-neuronal cells in the brain tissue. An overview of the bending stiffness of conventional neural probes and neural tissue reveals a remarkable mismatch in their mechanical properties, resulting in relative shear motion, chronic immune response and substantially altered distribution of neurons and glial cells at the probe interface (Box 2), all of which contribute to instability of chronic recordings of single-neuron activities ${ }^{79,80}$. Hence, some researchers have focused on developing probe technologies in which the mechanical stiffness is substantially lower than silicon or microwire probes ${ }^{81-90}$.

\section{Advances in electrode technologies with stable long-term recording}

A new paradigm for achieving chronically stable neural recording interfaces not only has addressed disparity in mechanical stiffness between neural probe and tissue, but also has introduced designs such that the neural probes 'look' and 'behave' like the neural tissue they are designed to interface with and interrogate. Specifically, brain tissue is extremely soft and comprises 3D neuronal networks involving micron-scale neuron somata and dendrites, and 'tissue-like electronics' approaches aim to develop neural probes with similar structural, mechanical and topological properties ${ }^{86}$.

The first realization of tissue-like electronics — mesh electronic neural probes — were designed to have the largest feature sizes similar to individual neuron soma, bending stiffness values on par with the brain tissue (Box 2), and >90\% 3D macroporosity to enable neurite interpenetration ${ }^{81}$ and to prevent accumulation of pro-inflammatory signalling molecules ${ }^{82,91}$. The free-standing polymer-metal-polymer structure of mesh electronics has 
exposed recording electrodes and I/O pads, whereas all metal lines interconnecting electrodes and I/O pads are encapsulated by the two polymer layers (Fig. 3b, left). These mesh probes are fabricated as two-dimensional (2D) structures on silicon wafers using standard photolithography, as for Michigan-type silicon probes, but are then released to an aqueous solution, where they can adopt a suspended polymer-like 3D morphology. The ultraflexible mesh electronics can be precisely delivered in vivo into target brain regions by controlled stereotaxic syringe injection ${ }^{92}$, after which the capillary needle is removed, leaving from the external part of the mesh outside the skull for connection with the recording interface. The tissue-like flexibility of these mesh probes also enables facile connection to low-profile low-mass ( 1 g) headstages for multiplexed plug- and-play I/O interfaces with recording instruments (Fig. 3b) ${ }^{93}$.

The mesh design has led to advances with respect to chronic tissue response and single-unit recording stability. Mesh electronics-tissue interfaces exhibit no chronic immune response, evidenced by immunohistology showing an endogenous distribution of all key cell types around the mesh probe, as well as neurites and neuron somata in the interior probe volume, up to at least 1 year post-injection (Table 1$)^{83,84}$. In addition, mesh electronics has yielded long-term stable recording at the single-neuron level in mice for at least 8 months, with consistent tracking of -200 neurons per mouse (Table 1) ${ }^{83,87}$. Analyses of the intrinsic biophysical properties of individual neurons, including spike waveform, spike amplitude, SNR, firing rate and stimulus-evoked firing responses ${ }^{94}$, and their characteristic interactions with the encompassing neural network, such as phase locking to theta oscillations and

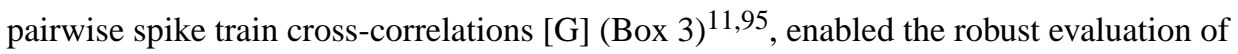
long-term recording stability, compared with conclusions of stability made on a collective basis where individual neurons from each recording channel or probe are not differentiated $49,58,61,96$.

A correlation between reduced chronic immune response and improved chronic recording stability on a single-neuron basis observed for mesh electronics has also been observed with several other recent electrode technologies ${ }^{88-90,97}$. Recording electrodes made of ultrasmall ( $<10 \mu \mathrm{m}$ diameter) carbon fibres induced a reduced chronic immune response compared with conventional silicon probes with much larger cross-sectional area, owing to a lower bending stiffness and thus greater flexibility of the former. Carbon fibres electrically connected to a standard recording interface using conductive silver paint ${ }^{90}$ and inserted into target brain regions of rats ${ }^{97}$ and songbirds ${ }^{90}$ consistently tracked single-unit action potentials from the same individual neurons over several weeks, as assessed by comparisons of spike waveforms, clustering of spikes by principal component analysis [G] (PCA), and correlation of spike firing with vocal output ${ }^{90,97}$. However, it is difficult to scale up ultrasmall fibre probes into multiplexed arrays, because photolithography is not suitable for patterning large arrays, and multiple fibres would need to be bundled together to increase multiplexity without scaling up implant size (which would otherwise proportionally increase damage to the brain tissue).

Larger, multifunctional polymer fibre probes, fabricated by thermal drawing process [G] offered simultaneous optical, electrical and chemical interrogation of neural circuits and were evaluated for their long-term single-neuron recording stability in vivo. The probes had 
a cross-sectional diameter of $\sim 200 \mu \mathrm{m}$, resulting in a reduced bending stiffness. The electrodes in the probe were connected to a standard pin connector via copper wires using silver paint and solder to afford low contact resistance ${ }^{88}$. After insertion, chronic interrogation of the same individual neurons was demonstrated by analyses of spike waveforms, which were confirmed by PCA, firing rate and optogenetically evoked action potentials ${ }^{88}$. Analysis of recorded data from 1 of the 6 electrodes in the multifunctional fibre probe showed that the same neurons were stably followed over 3 months ${ }^{88}$. This recording stability was also attributed to a reduced chronic immune response, although some proliferation of astrocytes and microglia remained at the probe interface (Table 1$)^{88,98}$.

Similar metrics of single-neuron tracking were used to assess an ultraflexible nanoelectronic probe design that was fabricated with standard photolithography and delivered intracortically via a shuttle device. Eleven of 16 electrodes from two high-density probes implanted in the same mouse brain demonstrated reliable detection and stable tracking of single units over 4 months ${ }^{89,99}$. More recently, polyimide electrode arrays with up to 1024 channels enabled recordings of singleunits up to 283 days, and tracking of $20 \%$ of the same units continuously for 10 days, based on day-to-day spike waveform evolution and firing rate similarity ${ }^{55}$. The recent adaptations of rigorous metrics for single-unit-based analyses of the chronic stability (Box 3 ) of emerging neural probes provide robust measures of the longterm performance of these technologies and potential future opportunities for neuroscience.

\section{Neuroscientific importance and further development}

Chronic recording of the same individual neurons over extended time periods offers new opportunities for understanding key neurobiological processes.

For example, brain ageing may be associated with cognitive decline and mood disorders and occurs over years and across centimeter-scale coordinated regions in the brain; however, it involves cellular electrophysiological changes that must be quantified on the millisecond and micrometer scales of individual neurons ${ }^{100,101}$. Studies of brain ageing using conventional recording electrode technologies would need to be cross-sectional (that is, comparing different age groups) because the rigid mechanical properties of these electrodes and the immune response they elicit lead to instability of chronic single-unit recording ${ }^{102}$. Mesh electronic probes yield chronically stable neural recording on a year-timescale, opening up the potential for longitudinal studies of brain ageing in rodents and other model species with single-neuron resolution. For example, age-associated changes of functional properties of individual neurons were tracked in mice, and revealed a progressive decrease in spontaneous firing rate and increases in the widths of spikes, in a highly neuron-specific manner ${ }^{83}$. Similar studies could help to reveal the underlying neuronal basis of age-related cognitive decline in the future.

In addition, chronic recording of individual retinal ganglion cells (RGCs) in awake mice using mesh electronics in the vitreous body of the eye offers a unique opportunity to study the interaction between the retina and related brain regions involved in visual processing and regulation ${ }^{103}$. For example, by tracking the firing responses of the same RGCs to certain visual stimuli over multiple day-night cycles, RGC responses were shown to exhibit circadian rhythms ${ }^{103}$. Moreover, simultaneous electrophysiological recording in the retina 
and visual areas of the brain could offer valuable insights on the cellular and synaptic mechanisms that generate direction selectivity in visual sensory processing ${ }^{104,105}$.

Several challenges remain for ultraflexible recording electrodes with reduced chronic immune response and long-term recording stability. First, acute needle insertion damage during injection of mesh electronics may contribute to the initial amplitude increase during the first weeks after injection and associated neural tissue recovery ${ }^{84}$. The needles that have been used to deliver mesh electronics ${ }^{83,87,103}$ are larger (ranging 330-650 $\mu \mathrm{m}$ ) than the shank cross-section of Michigan-type silicon probes such as Neuropixels $(70 \mu \mathrm{m} \times 20 \mu \mathrm{m})$ and NeuroSeeker $(100 \mu \mathrm{m} \times 50 \mu \mathrm{m})^{49,50}$. These relatively large needle sizes may lead to unfavorable acute neural tissue damage and thus impose challenges to acute recordings of single-unit activity after injection. Nonetheless, the needle used for mesh delivery is removed immediately after injection, and challenges to acute recordings might be mitigated by using designs with further optimized structural features and mechanical properties, and injection needles with smaller diameters. Second, existing highly flexible probes have generally been limited by a smaller number of recording electrodes than Neuropixels-type probes, except in a few cases ${ }^{87,106}$. Therefore, future electrode technologies with long-term recording stability could benefit from improvement of spatial integration with increased channel multiplexity that does not alter the chronic recording stability of the original electrode scaffolds.

\section{Multifunctional integration}

Understanding the causal connectivity of neural networks and the relationships among neural activity patterns, brain functions and behaviours is important for elucidating the inner workings of the brain ${ }^{107}$. Studying causality requires the deconstruction of the neural circuits with gain-of-function and loss-of-function studies using electrical, optogenetic and/or pharmacological stimulations with simultaneous electrical recording ${ }^{108-110}$. The need to understand causality in the nervous system has driven the development of multifunctional neural probes that incorporate stimulation electrodes, light-emitting diodes (LEDs), optical fibres or waveguides, and microfluidic channels into the existing architecture of neural recording probes ${ }^{111}$.

\section{Advances in electrode technologies with multifunctional integration}

Directly modulating neuronal activity by injecting charge via electrodes on integrated probes has a long history in neuroscience ${ }^{12,113}$. However, arguably the biggest impact to date has been through deep-brain stimulation (DBS) to treat neurological diseases, including Parkinson disease and depression ${ }^{114}$. Current efforts in this latter direction have focused on multifunctional DBS probes that can both record LFPs and electrically stimulate target regions, with the goal of providing closed-loop feedback [G] for treatment ${ }^{115}$.

Several key challenges affect the utility of multifunctional electrical recording and stimulation probes in fundamental neuroscience studies. First, chronic gliosis at the probetissue interface (Box 2), along with lack of precision in charge injection, can lead to excitation and/or inhibition of neural circuit components without a priori predictability ${ }^{113,114,116}$. Second, issues arising from chronic instability in tracking single 
units can necessitate the use of more global LFPs and thus preclude the precise tracking and modulation of circuits (Fig. 2a) ${ }^{115}$. Third, multifunctional probes with electrical stimulation alone are unable to modulate the activity of specific subtypes of neurons.

In one study, a mesh electronic probe was incorporated with low-impedance stimulation electrodes to enable simultaneous injection of low-level current and recording of single neurons. This simultaneous recording and stimulation platform enabled tracking of highly stable and predictable single-neuron responses to intermittent electrical stimulation over at least 3 months ${ }^{83}$. In addition, a wireless neural recording and stimulation interface has been realized in the 'Neural Dust' platform, which has a dimension of $0.8 \mathrm{~mm} \times 3 \mathrm{~mm} \times 1 \mathrm{~mm}$. In this platform, an implanted sensor of $0.2 \mathrm{~mm} \times 0.2 \mathrm{~mm}$ is powered by ultrasound and transmits electrophysiological signal by encoding it to the reflected ultrasound using built-in piezoelectric crystals ${ }^{117-119}$. Despite advantages of a wireless interface with reduced footprint of electrical connection to achieve greater penetration depth, the chronic recording stability and immune response after implantation of the 'Neural Dust' probe have yet to be evaluated. Further miniaturization of its size will also be needed to improve its interface with the neural tissue for future development ${ }^{117}$.

Optogenetics enables precise deconstruction of neural circuitry with neuron-subtype specificity ${ }^{34}$. As optical modulation is orthogonal to electrical recording, it generally interferes less with simultaneous readouts of neural activity than does electrical stimulation. However, electrical artefacts still exist, owing to photovoltaic effect (also known as the Becquerel effect) of light on metal recording electrodes ${ }^{120}$. Early, more basic efforts to afford optogenetic modulation combined with neural recording electrodes involved simple physical attachment of light emitting diodes (LEDs) to conventional Michigan-type silicon probes $^{121}$. More recently, advanced fabrication methods have been used to monolithically integrate micro-LEDs on the same silicon neural probe with a cross-sectional area of $30 \mu \mathrm{m}$ $\times 70 \mu \mathrm{m}$ for highly localized optogenetic modulation and simultaneous electrophysiological recordings in vivo, with $50 \mu \mathrm{m}$ resolution (Table 1$)^{122}$.

Other groups have tried combining optical fibres and waveguides with electrode technologies, motivated by the smaller footprint of optical waveguides and the similar aspect ratios of optical fibres and microwire electrodes. Combining a $200-\mu \mathrm{m}$ diameter multimode optical fibre with four $25-\mu \mathrm{m}$ diameter tetrode bundles, a hybrid neural probe named 'optetrode' enabled optogenetic modulation of neural activity in the medial prefrontal cortex of behaving mice, with each of the four tetrodes simultaneously recording single-unit responses to the optical stimulation ${ }^{123}$. Similarly, optical fibres have been etched to a tip size of 5-20 $\mu \mathrm{m}$ in diameter and physically attached to silicon probes to yield a hybrid optoelectrical interface ${ }^{124125}$. Using a thermal drawing process, multifunctional fibres incorporating recording electrodes and optical waveguides with submillimeter diameters and good flexibility, owing to the use of polymer materials, were fabricated and used to simultaneously record optogenetically manipulated neural activities in the mouse brain and

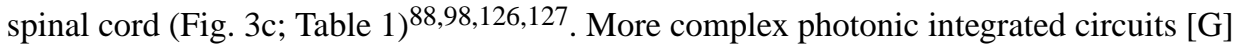
have been incorporated into the Michigan array as a monolithic structure via photolithography, including a waveguide mixer or a waveguide splitter to selectively deliver different wavelengths ${ }^{128}$ or the same wavelength of light to different sites of the brain ${ }^{129}$, 
respectively, to modulate neural activity. In addition, optically transparent and electrically conductive zinc oxide pillars $(125-\mu \mathrm{m}$ diameter) were arranged in a $4 \times 4$ Utah-type MEA probe through a combination of physical dicing and chemical etching processes. The array was used to simultaneously deliver light and detect electrical signals in targeted cortical areas (Table 1) $)^{130}$.

As a middle ground between the non-specific electrical stimulation and neuron-subtype specific optogenetic stimulation, neural activity can be modulated by delivery of channel- or receptor-targeted biologies into a discrete brain region. This approach affords precise manipulation of biochemical pathways in the brain without genetic modification of target neurons ${ }^{14}$. To this end, Michigan-type silicon probes were fabricated with integrated microfluidic channels, which were formed by deep reactive ion etching [G] (DRIE) of the silicon substrate. Channels in the silicon substrate were connected to a PDMS (polydimethylsiloxane) microfluidic interface, which was then connected to external catheter tubing by a hypodermic needle, thus enabling delivery of different neuroactive biochemicals (Fig. 3c; Table 1) ${ }^{131,132}$. For example, microinjection of seizure-inducing drugs such as baclofen along with simultaneous electrophysiology successfully enabled the observation of characteristic ictal $[\mathrm{G}]$ patterns ${ }^{131}$. In addition, delivery of different neuromodulatory drugs yielded increases or decreases in singleunit activities that were simultaneously monitored by the built-in electrodes ${ }^{132}$.

\section{Neuroscientific importance and further development}

Multifunctional electrode technologies are generally still in relatively early stages of development and may be more difficult to implement than established tools with specific functions; thus, the potential of these multifunctional probes for neuroscience is perhaps yet to be realized. Nevertheless, closed-loop electrophysiological recordings with electrical, optical or biochemical modulation of neural activity have substantial potential for helping to illuminate the connectivity and communication dynamics between neural circuits and neurons that comprise the circuits, as well as decoding the underlying causal link between single-neuron activity and behaviour ${ }^{63}$. In addition, the bidirectional interfaces of multifunctional neural probes also offer future opportunities to translate neuroscientific advances into neurological application; for example, towards more efficacious DBS devices and the delivery of neurophysiology-intervening biologies for treatment of neurological and neuropsychiatric diseases ${ }^{133}$. Such approaches may further our ability to control and even correct the deleterious functions of diseased neural circuits in real time.

Multifunctional electrode technologies combining electrical recording and different modulation modalities each have their own strengths and limitations. Neural probes with integrated electrical stimulation sites enable facile modulation of brain function in a welldefined behavioral context, and may be more easily translated to clinical neurological applications, yet they lack cell-or neuron-subtype specificity in stimulation. By covalently linking functional molecules to the surface of recording and stimulation electrodes, these electrodes could recognize and target specific cell-surface receptors through specific ligandreceptor interactions ${ }^{134}$. As a result, biochemically modified electrode surfaces may enable neuron subtype electrophysiology in vivo, if the probe does not elicit a chronic immune 
response ${ }^{86}$. Multifunctional electrodes with waveguides or micro-LEDs can optogenetically activate or inhibit specific neuron subtypes to investigate neural circuits, although existing probes have sacrificed number of recording electrodes to achieve 'multifunctionality'. Furthermore, most existing multifunctional electrodes still elicit chronic gliosis owing to a large footprint and rigid probe materials, although exceptions have been made to develop LED probes that are more flexible and thinner ${ }^{135,136}$. Wafer-level bonding is usually employed to power monolithically integrated micro-LEDs on rigid silicon neural probes ${ }^{122}$ and micro-LEDs arrays on flexible substrates ${ }^{136,137}$. Alternatively, however, wireless power systems have also been used to power and control micro-LEDs on flexible neural probes ${ }^{135,138,139}$. Nevertheless, micro-LED-incorporated neural probes on more flexible and thinner substrates still exhibit chronic gliosis ${ }^{135}$, suggesting that further changes to the probe design are needed. Moreover, the electrical crosstalk between LED power supply lines and the interconnects of recording electrodes on the same shaft could lead to artefacts in electrophysiological recording with simultaneous optogenetic stimulation. By contrast, unlike electrically powered LEDs integrated in existing probe architectures, flexible fiber probes and waveguides require precise alignment at the light input port to minimize photon loss, posing further challenges ${ }^{88,98,128,130}$. In addition, electrode probes with integrated microfluidic channels can specifically modulate neural activity without genetic modification, yet are complicated to fabricate.

Future development of these multifunctional neural recording electrodes with optical and biochemical modulation should draw from recent advances in micro- and nanofabrication to afford a facile parallel interface with high multiplexity of electrical, optical and biochemical channels. At the same time, such development should remain cognizant of the key issues of probe stiffness and size in determining the potential for probing the endogenous circuity and cellular makeup of the brain.

\section{Conclusions and future directions}

Only when we realize the immense disparity between the neural tissue and existing electrode technologies can we begin to develop next-generation neural probes to revolutionize neuroscientific research. By imitating the intricate design and complex function of the brain, newly developed electrode technologies are beginning to look and behave like the neural networks we seek to probe, with an unprecedented large number of recording electrodes, neuron- and neural tissue-like designs to form a chronically stable recording interfaces at the single neuron level, and bidirectional flow of information via multifunctional electrical, optical and biochemical inputs.

We envisage that in future there will be a convergence of the greatest strengths of neurotechnologies discussed above, especially a focus on blurring their structural, mechanical and biochemical dissimilarities with the neurons and neural circuity that these probes seek to illuminate. Further technological developments in three major directions are needed to address existing limitations mentioned above to develop 'ideal' neural probes. First, a large number of electrodes allowed by latest CMOS fabrication technologies should be incorporated to probe globally coordinated brain regions, whereas electrodes should be reduced in size to approach that of a single neuron soma or axon and functionalized with 
molecules to afford specific targeting of different cell types and neuron subtypes. Second, electrodes should afford long-term stable recording and modulation of neural activity at the single-neuron level, with minimal-to-no perturbation of endogenous distribution of all cell types. Third, functionalities including electrical recording, electrical or optical stimulation and pharmacological modulation should be incorporated into single probe designs, or in multiple probes for different functions (as sometimes all-in-one is less favourable than individual probes with single functions).

Such efforts will eventually afford studies of the brain in its native state and allow basic advances, such as understanding learning, memory storage and recall at the single-neuron level, and the changes that occur over the life spans of animals. 'Ideal' neural recording technologies will enable new neuroscientific studies of neural systems by interrogating the global coordination of multiple distant yet interconnected brain regions, tracking long-term neural circuit evolution over extended time periods and deconstructing the underlying neural circuits with multimodal modulation of brain activities ${ }^{140-142}$.

\section{Supplementary Material}

Refer to Web version on PubMed Central for supplementary material.

\section{Acknowledgements}

We thank Dr. S. R. Patel for helpful discussions. C.M.L. acknowledges support of this work by the Air Force Office of Scientific Research (FA9550-14-1-0136) and a National Institutes of Health Director's Pioneer Award (1DP1EB025835-01). G.H. acknowledges support of this work by the Pathway to Independence Award (Parent K99/R00) from the National Institute on Aging of the National Institutes of Health (4R00AG056636-03).

\section{Glossary terms:}

\section{Tetrode}

A microelectrode array consisting of four closely bundled and independently addressable microwire electrodes. Action potentials from the same neuron can be detected with varying amplitudes across all four electrodes

\section{Michigan-type microelectrode array}

A microelectrode array with recording sites distributed along the length of each silicon shank

\section{Utah-type-microelectrode array}

A (usually $10 \times 10$ ) microelectrode array of silicon shanks with recording sites only located at the tip of each silicon shank

\section{Local field potentials}

(LFPs). Extracellular electric field oscillations in the $0-100 \mathrm{~Hz}$ frequency band, which mainly arise from collective transmembrane ionic currents and act as a medium for networklevel communication

\section{Fourier transform}


A mathematical method that decomposes a waveform, which is usually a function of time such as the neural recording trace, into the frequencies that make it up

\section{Spectrogram}

A visual representation of frequencies of time-varying neural signals in a spectrum. A spectrogram is generated after performing Fourier transform of the neural recording trace

\section{Transistors}

Semiconductor devices that can be used to switch or amplify electronic signals and thus act as basic building blocks of integrated circuits in modern electronic devices

\section{Impedance}

Effective resistance of an electrical circuit to current when an oscillating voltage is applied. It has the same Ohm units as resistance but applies to AC circuits

\section{Channels}

Separate paths in neural probes where electrical, optical and chemical signals can flow to measure or modulate neural activity in an independently addressable manner

\section{Multiplexity}

Number of independent channels in a given neural probe. The multiplexity of a neural probe represents the information throughput at the brain-probe interface

\section{Complementary metal-oxide-semiconductor}

(CMOS). A technology with design style that uses complementary pairs of p-type and ntype metal oxide semiconductor field effect transistors for low-energy-cost logical functions in integrated circuits

\section{Ripple}

Fast and synchronous oscillatory pattern of the LFP in the CA1 pyramidal layer of the hippocampus usually in the frequency range of 100 to $200 \mathrm{~Hz}$

\section{Photovoltaic effect}

A process that generates voltage or electric current in a material upon exposure to light. Not to be confused with photoelectric effect where electrons are ejected from the material

\section{Field-effect transistors}

Three-terminal semiconductor devices in which the current flow (output) between the source and drain electrodes is modulated by the voltage (input) at the gate electrode

\section{Spike train cross-correlation}

Pairwise comparison of spike trains that reveals the latency in firing activity and potential monosynaptic excitatory or inhibitory interactions between two neurons

\section{Principal component analysis}

(PCA). A statistical procedure to reduce the dimensionality and extract features of the extracellular spike waveform, thus assigning spikes to different neurons based on waveform difference 


\section{Thermal drawing process}

A process commonly used in optical fibre production, whereby macroscopic materials are heated and stretched to wires and sheets with greatly reduced thickness

\section{Closed-loop feedback}

Electrical, optical and biochemical input to the nervous system that is adjusted by and used to control the measured output of neural activity

\section{Photonic integrated circuit}

An optical counterpart of electronic integrated circuit, in which multiple photonic devices with distinct functions are integrated in the same circuitry

\section{Deep reactive ion etching}

(DRIE). A type of reactive ion etching process used to create sharp-edged holes and trenches in the substrate usually with high anisotropy and high aspect ratio

\section{Ictal}

The acute episode during which an epileptic seizure occurs. The ictal period features abnormal bursts of electrical impulses in the brain and loss of consciousness

\section{Young's modulus}

An intrinsic material property that measures the ability of a material to resist its change (increase or decrease) in length under tensile or compressive forces

\section{Bending stiffness}

The measure of the ability of a structure to resist bending deformation to applied force. It depends on the Young's modulus of the material and geometrical features of the structure

\section{References}

Highlighted references: For references that are particularly worth reading ( 10 of the total), please provide a single bold sentence that indicates the significance of the work, underneath the reference in the main list below.

1. Galvani L De viribus electricitatis in motu musculari commentarius Pars prima. (Bologna: Accademia delle Scienze, 1791).

2. Helmholtz H. v.. Messungen über Fortpflanzungsgeschwindigkeit der Reizung in den Nerven. Archiv für Anatomie, Physiologie und wissenschaftliche Medicin 19, 199-216 (1852).

3. Erlanger J \& Gasser HS Electrical signs of nervous activity (Milford H, Oxford university press, 1937).

4. Hodgkin AL \& Huxley AF Action potentials recorded from inside a nerve fibre. Nature 144, 710 711 (1939).

5. Hubel DH Tungsten Microelectrode for Recording from Single Units. Science 125, 549-550 (1957). [PubMed: 17793797]

6. Hubel DH \& Wiesel TN Receptive Fields, Binocular Interaction and Functional Architecture in Cats Visual Cortex. J. Physiol 160, 106-154 (1962). [PubMed: 14449617]

7. Mcnaughton BL, Okeefe J \& Barnes CA The Stereotrode - a New Technique for Simultaneous Isolation of Several Single Units in the Central Nervous-System from Multiple Unit Records. J. Neurosci. Meth 8, 391-397 (1983).

8. Wise KD, Angell JB \& Starr A An Integrated-Circuit Approach to Extracellular Microelectrodes. IEEE Trans. Biomed. Eng BME-17, 238-247 (1970). 
9. Campbell PK, Jones KE \& Normann RAA 100 Electrode Intracortical Array - Structural Variability. Biomed. Sci. Instrum 26, 161-165 (1990). [PubMed: 2334761]

10. Buzsaki G, Anastassiou CA \& Koch C The origin of extracellular fields and currents - EEG, ECoG, LFP and spikes. Nat. Rev. Neurosci 13, 407-420 (2012). [PubMed: 22595786] This review article discussed the neurophysiological basis of different types of electrical signals in the brain, and how these signals are measured with different electrode technologies.

11. Buzsaki G Theta oscillations in the hippocampus. Neuron 33, 325-340 (2002). [PubMed: 11832222]

12. Yuste R From the neuron doctrine to neural networks. Nat. Rev. Neurosci 16, 487-497 (2015). [PubMed: 26152865] A historical overview that summarizes the evolution of fundamental neuroscience viewpoint from the neuron doctrine to neural network models, with a focus on how this evolution has been fueled by the emergence of multineuronal recording methods.

13. Harris KD, Quiroga RQ, Freeman J \& Smith SL Improving data quality in neuronal population recordings. Nat. Neurosci 19, 1165-1174 (2016). [PubMed: 27571195]

14. Carter M \& Shieh JC Guide to research techniques in neuroscience (Academic Press, 2015)

15. Buzsaki G Large-scale recording of neuronal ensembles. Nat. Neurosci 7, 446-451 (2004). [PubMed: 15114356]

16. Rossant C et al. Spike sorting for large, dense electrode arrays. Nat. Neurosci 19, 634-641 (2016). [PubMed: 26974951]

17. Logothetis NK, Pauls J, Augath M, Trinath T \& Oeltermann A Neurophysiological investigation of the basis of the fMRI signal. Nature 412, 150-157 (2001). [PubMed: 11449264]

18. Keller CJ, Chen C, Lado FA \& Khodakhah K The Limited Utility of Multiunit Data in Differentiating Neuronal Population Activity. Plos One 11, e0153154 (2016). [PubMed: 27111446]

19. Ponce CR, Lomber SG \& Livingstone MS Posterior Inferotemporal Cortex Cells Use Multiple Input Pathways for Shape Encoding. J. Neurosci 37, 5019-5034 (2017). [PubMed: 28416597]

20. Gold C, Henze DA, Koch C \& Buzsaki G On the origin of the extracellular action potential waveform: A modeling study. J. Neurophysiol 95, 3113-3128 (2006). [PubMed: 16467426]

21. Harris KD, Henze DA, Csicsvari J, Hirase H \& Buzsaki G Accuracy of tetrode spike separation as determined by simultaneous intracellular and extracellular measurements. J. Neurophysiol 84, 401-414 (2000). [PubMed: 10899214]

22. Hubel DH \& Wiesel TN Receptive Fields of Single Neurones in the Cats Striate Cortex. J. Physiol 148, 574-591 (1959). [PubMed: 14403679]

23. O'Keefe J \& Dostrovsky J The hippocampus as a spatial map: Preliminary evidence from unit activity in the freely-moving rat. Brain Res. 34, 171-175 (1971). [PubMed: 5124915]

24. Desimone R, Albright TD, Gross CG \& Bruce C Stimulus-Selective Properties of Inferior Temporal Neurons in the Macaque. J. Neurosci 4, 2051-2062 (1984). [PubMed: 6470767]

25. Schultz W Responses of Midbrain Dopamine Neurons to Behavioral Trigger Stimuli in the Monkey. J. Neurophysiol 56, 1439-1461 (1986). [PubMed: 3794777]

26. Newsome WT, Britten KH \& Movshon JA Neuronal correlates of a perceptual decision. Nature 341, 52-54 (1989). [PubMed: 2770878]

27. Hafting T, Fyhn M, Molden S, Moser MB \& Moser EI Microstructure of a spatial map in the entorhinal cortex. Nature 436, 801-806 (2005). [PubMed: 15965463]

28. Quiroga RQ, Reddy L, Kreiman G, Koch C \& Fried I Invariant visual representation by single neurons in the human brain. Nature 435, 1102-1107 (2005). [PubMed: 15973409]

29. Hochberg LR et al. Neuronal ensemble control of prosthetic devices by a human with tetraplegia. Nature 442, 164-171 (2006). [PubMed: 16838014]

30. Lin MZ \& Schnitzer MJ Genetically encoded indicators of neuronal activity. Nat. Neurosci 19, 1142-1153 (2016). [PubMed: 27571193]

31. Poldrack RA \& Farah MJ Progress and challenges in probing the human brain. Nature 526, 371379 (2015). [PubMed: 26469048]

32. Yang WJ \& Yuste R In vivo imaging of neural activity. Nat. Methods 14, 349-359 (2017). [PubMed: 28362436] 
33. Ji N, Freeman J \& Smith SL Technologies for imaging neural activity in large volumes. Nat. Neurosci 19, 1154-1164 (2016). [PubMed: 27571194]

34. Deisseroth K Optogenetics: 10 years of microbial opsins in neuroscience. Nat. Neurosci 18, $1213-$ 1225 (2015). [PubMed: 26308982]

35. Jorgenson LA et al. The BRAIN Initiative: developing technology to catalyse neuroscience discovery. Philos. Trans. R. Soc. Lond. B Biol. Sci 370, 20140164 (2015). [PubMed: 25823863]

36. Reardon S Worldwide brain-mapping project sparks excitement - and concern. Nature 537, 597 (2016). [PubMed: 27680917]

37. Grinvald A \& Hildesheim R VSDI: a new era in functional imaging of cortical dynamics. Nat. Rev. Neurosci 5, 874-885 (2004). [PubMed: 15496865]

38. Khan HN, Hounshell DA \& Fuchs ER Science and research policy at the end of Moore's law. Nat. Electron 1, 14 (2018).

39. Stevenson IH \& Kording KP How advances in neural recording affect data analysis. Nat. Neurosci 14, 139-142 (2011). [PubMed: 21270781]

40. Chen R, Canales A \& Anikeeva P Neural recording and modulation technologies. Nat. Rev. Mater 2, 16093 (2017).A comprehensive review article with a focus on recent materials-driven progress in neural probes.

41. Salatino JW, Ludwig KA, Kozai TDY \& Purcell EK Glial responses to implanted electrodes in the brain. Nat. Biomed. Eng 1, 862-877 (2017). [PubMed: 30505625] A timely review article that highlighted the latest evidence on the role of glial cells in neural circuits. Based thereon, it also provided insights on the design of implanted brain probes, from the perspective of the mechanical properties of the probe materials and the glial response in the neural tissue.

42. Eroglu C \& Barres BA Regulation of synaptic connectivity by glia. Nature 468, 223-231 (2010). [PubMed: 21068831]

43. Clarke LE \& Barres BA Emerging roles of astrocytes in neural circuit development. Nat. Rev. Neurosci 14, 311-321 (2013). [PubMed: 23595014]

44. Neves HP et al. The NeuroProbes Project: A Concept for Electronic Depth Control. 2008 30th Annual International Conference of the leee Engineering in Medicine and Biology Society, Vols 18, 1857-1857 (2008).

45. Torfs T et al. Two-Dimensional Multi-Channel Neural Probes With Electronic Depth Control. IEEE Trans. Biomed. Circ. Syst 5, 403-412 (2011).

46. Seidl K et al. CMOS-Based High-Density Silicon Microprobe Arrays for Electronic Depth Control in Intracortical Neural Recording-Characterization and Application. J. Microelectromech. Syst 21, 1426-1435 (2012).

47. Cheng MY et al. 3D probe array integrated with a front-end 100-channel neural recording ASIC. J. Micromech. Microeng 24, 125010 (2014).

48. Fiath $\mathrm{R}$ et al. Large-scale recording of thalamocortical circuits: in vivo electrophysiology with the two-dimensional electronic depth control silicon probe. J. Neurophysiol 116, 2312-2330 (2016). [PubMed: 27535370]

49. Jun JJ et al. Fully integrated silicon probes for high-density recording of neural activity. Nature 551, 232-236 (2017). [PubMed: 29120427] This work demonstrated highly multiplexed integration of 960 recording electrodes into the same Michigan-type microelectrode array.

50. Raducanu BC et al. Time Multiplexed Active Neural Probe with 1356 Parallel Recording Sites. Sensors (Basel) 17, 2388 (2017).

51. Rios G, Lubenov EV, Chi D, Roukes ML \& Siapas AG Nanofabricated neural probes for dense 3-D recordings of brain activity. Nano Lett. 16, 6857-6862 (2016). [PubMed: 27766885]

52. Stringer $\mathrm{C}$ et al. Spontaneous behaviors drive multidimensional, brain-wide population activity. bioRxiv, 306019 (2018).

53. Angotzi GN et al. A Synchronous Neural Recording Platform for Multiple High-Resolution CMOS Probes and Passive Electrode Arrays. IEEE Trans. Biomed. Circ. Syst 12, 532-542 (2018).

54. Steinmetz NA, Koch C, Harris KD \& Carandini M Challenges and opportunities for large-scale electrophysiology with Neuropixels probes. Curr. Opin. Neurobiol 50, 92-100 (2018). [PubMed: 29444488] 
55. Chung JE et al. High-density, long-lasting, and multi-region electrophysiological recordings using polymer electrode arrays. Neuron 101, https://doi.org/10.1016/j.neuron.2018.1011.1002 (2019).

56. Feiner R \& Dvir T Tissue-electronics interfaces: from implantable devices to engineered tissues. Nat. Rev. Mater 3, 17076 (2018).This review discussed the design principles for implantable electronic devices to interface with the biological tissue, and applications in electrophysiology and tissue engineering.

57. Viventi J et al. Flexible, foldable, actively multiplexed, high-density electrode array for mapping brain activity in vivo. Nat. Neurosci 14, 1599-U1138 (2011). [PubMed: 22081157]

58. Khodagholy D et al. NeuroGrid: recording action potentials from the surface of the brain. Nat. Neurosci 18, 310-315 (2015). [PubMed: 25531570] First demonstration of single-unit electrophysiology from the cortical surface with an ECoG array.

59. Gao P et al. A theory of multineuronal dimensionality, dynamics and measurement. bioRxiv, 214262 (2017).

60. Dickey AS, Suminski A, Amit Y \& Hatsopoulos NG Single-Unit Stability Using Chronically Implanted Multielectrode Arrays. J. Neurophysiol 102, 1331-1339 (2009). [PubMed: 19535480]

61. Vetter RJ, Williams JC, Hetke JF, Nunamaker EA \& Kipke DR Chronic neural recording using silicon-substrate microelectrode arrays implanted in cerebral cortex. IEEE Trans. Biomed. Eng 51, 896-904 (2004). [PubMed: 15188856]

62. Khodagholy D, Gelinas JN \& Buzsaki G Learning-enhanced coupling between ripple oscillations in association cortices and hippocampus. Science 358, 369-372 (2017) [PubMed: 29051381]

63. Avena-Koenigsberger A, Misic B \& Sporns O Communication dynamics in complex brain networks. Nat. Rev. Neurosci 19, 17-33 (2018).

64. Frankland PW \& Bontempi B The organization of recent and remote memories. Nat. Rev. Neurosci 6, 119-130 (2005). [PubMed: 15685217]

65. Marblestone AH et al. Physical principles for scalable neural recording. Front. Comput. Neurosc 7, 137 (2013).

66. Welkenhuysen $\mathrm{M}$ et al. An integrated multi-electrode-optrode array for in vitro optogenetics. Sci. Rep 6, 20353 (2016). [PubMed: 26832455]

67. Zhang AQ \& Lieber CM Nano-Bioelectronics. Chem. Rev 116, 215-257 (2016). [PubMed: 26691648]

68. Kruskal PB, Jiang Z, Gao T \& Lieber CM Beyond the Patch Clamp: Nanotechnologies for Intracellular Recording. Neuron 86, 21-24 (2015). [PubMed: 25856481]

69. Patolsky F et al. Detection, stimulation, and inhibition of neuronal signals with high-density nanowire transistor arrays. Science 313, 1100-1104 (2006). [PubMed: 16931757]

70. Tian BZ et al. Three-Dimensional, Flexible Nanoscale Field-Effect Transistors as Localized Bioprobes. Science 329, 830-834 (2010). [PubMed: 20705858]

71. Parameswaran R \& Tian BZ Rational Design of Semiconductor Nanostructures for Functional Subcellular Interfaces. Acc. Chem. Res 51, 1014-1022 (2018). [PubMed: 29668260]

72. Khodagholy $\mathrm{D}$ et al. In vivo recordings of brain activity using organic transistors. Nat. Commun 4 , 1575 (2013). [PubMed: 23481383]

73. Benfenati $\mathrm{V}$ et al. A transparent organic transistor structure for bidirectional stimulation and recording of primary neurons. Nat. Mater 12, 672-680 (2013). [PubMed: 23644524]

74. Cohen-Karni T et al. Synthetically Encoded Ultrashort-Channel Nanowire Transistors for Fast, Pointlike Cellular Signal Detection. Nano Lett. 12, 2639-2644 (2012). [PubMed: 22468846]

75. Hong GS, Antaris AL \& Dai HJ Near-infrared fluorophores for biomedical imaging. Nat. Biomed. Eng 1, 0010 (2017).

76. Hoover EE \& Squier JA Advances in multiphoton microscopy technology. Nat. Photonics 7, 93101 (2013). [PubMed: 24307915]

77. Hochbaum DR et al. All-optical electrophysiology in mammalian neurons using engineered microbial rhodopsins. Nat. Methods 11, 825-833 (2014). [PubMed: 24952910]

78. Herry C \& Johansen JP Encoding of fear learning and memory in distributed neuronal circuits. Nat. Neurosci 17, 1644-1654 (2014). [PubMed: 25413091] 
79. Jackson A \& Fetz EE Compact movable microwire array for long-term chronic unit recording in cerebral cortex of primates. J. Neurophysiol 98, 3109-3118 (2007). [PubMed: 17855584]

80. Chestek CA et al. Long-term stability of neural prosthetic control signals from silicon cortical arrays in rhesus macaque motor cortex. J. Neural Eng 8, 045005 (2011). [PubMed: 21775782]

81. Liu J et al. Syringe-injectable electronics. Nat. Nanotechnol 10, 629-636 (2015). [PubMed: 26053995]

82. Xie $\mathrm{C}$ et al. Three-dimensional macroporous nanoelectronic networks as minimally invasive brain probes. Nat. Mater 14, 1286-1292 (2015). [PubMed: 26436341]

83. Fu T-M et al. Stable long-term chronic brain mapping at the single-neuron level. Nat. Methods 13, 875-882 (2016). [PubMed: 27571550] This work demonstrated chronically stable tracking of the same individual neurons over 8 months from the mouse brain with mesh electronics, and presents a comprehensive set of rigorous metrics for single-unit-based analyses.

84. Zhou T et al. Syringe-injectable mesh electronics integrate seamlessly with minimal chronic immune response in the brain. Proc. Natl. Acad. Sci. USA 114, 5894-5899 (2017). [PubMed: 28533392]

85. Hong G, Yang X, Zhou T \& Lieber CM Mesh electronics: a new paradigm for tissue-like brain probes. Curr. Opin. Neurobiol 50, 33-41 (2017). [PubMed: 29202327]

86. Hong G, Viveros RD, Zwang TJ, Yang X \& Lieber CM Tissue-like Neural Probes for Understanding and Modulating the Brain. Biochemistry 57, 3995-4004 (2018). [PubMed: 29529359]

87. Fu T-M, Hong G, Viveros RD, Zhou T \& Lieber CM Highly scalable multichannel mesh electronics for stable chronic brain electrophysiology. Proc. Natl. Acad. Sci. USA 114, E10046E10055 (2017). [PubMed: 29109247]

88. Park S et al. One-step optogenetics with multifunctional flexible polymer fibers. Nat. Neurosci 20 , 612-619 (2017). [PubMed: 28218915]

89. Luan L et al. Ultraflexible nanoelectronic probes form reliable, glial scar-free neural integration. Sci. Adv 3, e1601966 (2017). [PubMed: 28246640]

90. Guitchounts G, Markowitz JE, Liberti WA \& Gardner TJ A carbon-fiber electrode array for longterm neural recording.. J. Neural Eng. 10, 046016 (2013). [PubMed: 23860226]

91. Saxena T \& Bellamkonda RV Implantable Electronics a Sensor Web for Neurons. Nat. Mater 14, 1190-1191 (2015). [PubMed: 26585085]

92. Hong GS et al. Syringe Injectable Electronics: Precise Targeted Delivery with Quantitative Input/ Output Connectivity. Nano Lett. 15, 6979-6984 (2015). [PubMed: 26317328]

93. Schuhmann TG, Yao J, Hong GS, Fu TM \& Lieber CM Syringe-Injectable Electronics with a Plugand-Play Input/Output Interface. Nano Lett. 17, 5836-5842 (2017). [PubMed: 28787578]

94. Shadlen MN \& Newsome WT The variable discharge of cortical neurons: Implications for connectivity, computation, and information coding.!. Neurosci. 18, 3870-3896 (1998).

95. Bartho $\mathrm{P}$ et al. Characterization of neocortical principal cells and Interneurons by network interactions and extracellular features. J. Neurophysiol. 92, 600-608 (2004). [PubMed: 15056678]

96. Dzirasa K, Fuentes R, Kumar S, Potes JM \& Nicolelis MAL. Chronic in vivo multi-circuit neurophysiological recordings in mice. J. Neurosci. Meth 195, 36-46 (2011).

97. Kozai TDY et al. Ultrasmall implantable composite microelectrodes with bioactive surfaces for chronic neural interfaces. Nat. Mater 11, 1065-1073 (2012). [PubMed: 23142839]

98. Canales A et al. Multifunctional fibers for simultaneous optical, electrical and chemical interrogation of neural circuits in vivo. Nat. Biotechnol 33, 277-284 (2015). [PubMed: 25599177] This work demonstrated incorporation of optical fiber, recording electrodes and microfluidic channels into the same multifunctional neural probe.

99. Wei X et al. Nanofabricated Ultraflexible Electrode Arrays for High - Density Intracortical Recording. Adv. Sci, 1700625 (2018).

100. Morrison JH \& Baxter MG The ageing cortical synapse: hallmarks and implications for cognitive decline. Nat. Rev. Neurosci 13, 240-250 (2012). [PubMed: 22395804]

101. Burke SN \& Barnes CA Neural plasticity in the ageing brain. Nat. Rev. Neurosci 7, 30-40 (2006). [PubMed: 16371948] 
102. Wang M et al. Neuronal basis of age-related working memory decline. Nature 476, 210-U110 (2011). [PubMed: 21796118]

103. Hong $\mathrm{G}$ et al. A method for single-neuron chronic recording from the retina in awake mice. Science 360, 1447-1451 (2018). [PubMed: 29954976] This study used mesh electronics to chronically track the activity of the same RGCs in mouse retina after non-surgical, intravitreal injection.

104. Service RF Bioelectronics herald the rise of the cyborg. Science 358, 1233-1234 (2017). [PubMed: 29217547]

105. Lien AD \& Scanziani M Cortical direction selectivity emerges at convergence of thalamic synapses. Nature 558, 80-86 (2018). [PubMed: 29795349]

106. Zhao Z et al. Nanoelectronic Coating Enabled Versatile Multifunctional Neural Probes. Nano Lett. 17, 4588-4595 (2017). [PubMed: 28682082]

107. Kandel ER Principles of neural science (McGraw-Hill, 2013).

108. Grosenick L, Marshel JH \& Deisseroth K Closed-Loop and Activity-Guided Optogenetic Control. Neuron 86, 106-139 (2015). [PubMed: 25856490]

109. Aston-Jones G \& Deisseroth K Recent advances in optogenetics and pharmacogenetics. Brain Res. 1511, 1-5 (2013). [PubMed: 23422677]

110. Bernal-Casas D, Lee HJ, Weitz AJ \& Lee JH Studying Brain Circuit Function with Dynamic Causal Modeling for Optogenetic fMRI. Neuron 93, 522-532 (2017). [PubMed: 28132829]

111. Canales A, Park S, Kilias A \& Anikeeva P Multifunctional Fibers as Tools for Neuroscience and Neuroengineering. Acc. Chem. Res 51, 829-838 (2018). [PubMed: 29561583]

112. Miocinovic S, Somayajula S, Chitnis S \& Vitek JL History, applications, and mechanisms of deep brain stimulation. JAMA Neurol. 70, 163-171 (2013). [PubMed: 23407652]

113. Borchers S, Himmelbach M, Logothetis N \& Karnath HO OPINION Direct electrical stimulation of human cortex - the gold standard for mapping brain functions? Nat. Rev. Neurosci 13, 63-70 (2012).

114. Ashkan K, Rogers P, Bergman H \& Ughratdar I Insights into the mechanisms of deep brain stimulation. Nat. Rev. Neurol 13, 548-554 (2017). [PubMed: 28752857]

115. Ramirez-Zamora A et al. Evolving Applications, Technological Challenges and Future Opportunities in Neuromodulation: Proceedings of the Fifth Annual Deep Brain Stimulation Think Tank. Front. Neurosci 11, 734 (2018). [PubMed: 29416498]

116. Cicchetti F \& Barker RA The glial response to intracerebrally delivered therapies for neurodegenerative disorders: is this a critical issue? Front. Pharmacol 5, 139 (2014). [PubMed: 25071571]

117. Neely RM, Piech DK, Santacruz SR, Maharbiz MM \& Carmena JM Recent advances in neural dust: towards a neural interface platform. Curr. Opin. Neurobiol 50, 64-71 (2018). [PubMed: 29331738]

118. Seo D et al. Wireless Recording in the Peripheral Nervous System with Ultrasonic Neural Dust. Neuron 91, 529-539 (2016). [PubMed: 27497221]

119. Johnson BC et al. in 2018 IEEE Custom Integrated Circuits Conference (CICC). 1-4 (IEEE).

120. Packer AM, Roska B \& Hausser M Targeting neurons and photons for optogenetics. Nat. Neurosci 16, 805-815 (2013). [PubMed: 23799473]

121. Stark E, Koos T \& Buzsaki G Diode probes for spatiotemporal optical control of multiple neurons in freely moving animals. J. Neurophysiol 108, 349-363 (2012). [PubMed: 22496529]

122. Wu F et al. Monolithically Integrated mu LEDs on Silicon Neural Probes for High-Resolution Optogenetic Studies in Behaving Animals. Neuron 88, 1136-1148 (2015). [PubMed: 26627311]

123. Anikeeva $P$ et al. Optetrode: a multichannel readout for optogenetic control in freely moving mice. Nat. Neurosci 15, 163-U204 (2012).

124. Royer S et al. Multi-array silicon probes with integrated optical fibers: light-assisted perturbation and recording of local neural circuits in the behaving animal. Eur. J. Neurosci 31, 2279-2291 (2010). [PubMed: 20529127]

125. Wang $\mathrm{J}$ et al. Integrated device for combined optical neuromodulation and electrical recording for chronic in vivo applications. J. Neural Eng 9, 016001 (2012). [PubMed: 22156042] 
126. LeChasseur $Y$ et al. A microprobe for parallel optical and electrical recordings from single neurons in vivo. Nat. Methods 8, 319-U363 (2011). [PubMed: 21317908]

127. Lu C et al. Flexible and stretchable nanowire-coated fibers for optoelectronic probing of spinal cord circuits. Sci. Adv 3, e1600955 (2017). [PubMed: 28435858]

128. Kampasi K et al. Fiberless multicolor neural optoelectrode for in vivo circuit analysis. Sci. Rep 6, 30961 (2016). [PubMed: 27485264]

129. Son $\mathrm{Y}$ et al. In vivo optical modulation of neural signals using monolithically integrated twodimensional neural probe arrays. Sci. Rep 5, 15466 (2015). [PubMed: 26494437]

130. Lee J, Ozden I, Song YK \& Nurmikko AV Transparent intracortical microprobe array for simultaneous spatiotemporal optical stimulation and multichannel electrical recording. Nat. Methods 12, 1157-1162 (2015). [PubMed: 26457862]

131. Lee HJ et al. A multichannel neural probe with embedded microfluidic channels for simultaneous in vivo neural recording and drug delivery. Lab Chip 15, 1590-1597 (2015). [PubMed: 25651943]

132. Shin H et al. Neural probes with multi-drug delivery capability. Lab Chip 15, 3730-3737 (2015). [PubMed: 26235309]

133. Zrenner C, Belardinelli P, Muller-Dahlhaus F \& Ziemann U Closed-Loop Neuroscience and NonInvasive Brain Stimulation: A Tale of Two Loops. Front. Cell. Neurosci 10, 92 (2016). [PubMed: 27092055]

134. Cui Y, Wei QQ, Park HK \& Lieber CM Nanowire nanosensors for highly sensitive and selective detection of biological and chemical species. Science 293, 1289-1292 (2001). [PubMed: 11509722]

135. Kim TI et al. Injectable, Cellular-Scale Optoelectronics with Applications for Wireless Optogenetics. Science 340, 211-216 (2013). [PubMed: 23580530]

136. Gossler $\mathrm{C}$ et al. GaN-based micro-LED arrays on flexible substrates for optical cochlear implants. J. Phys. D Appl. Phys 47, 205401 (2014).

137. Klein E, Gossler C, Paul O \& Ruther P High-Density mu LED-Based Optical Cochlear Implant With Improved Thermomechanical Behavior. Front. Neurosci 12, 659 (2018). [PubMed: 30327585]

138. Il Park S et al. Soft, stretchable, fully implantable miniaturized optoelectronic systems for wireless optogenetics. Nat. Biotechnol 33, 1280-1286 (2015). [PubMed: 26551059]

139. Montgomery KL et al. Wirelessly powered, fully internal optogenetics for brain, spinal and peripheral circuits in mice. Nat. Methods 12, 969-974 (2015). [PubMed: 26280330]

140. Geva-Sagiv M, Las L, Yovel Y \& Ulanovsky N Spatial cognition in bats and rats: from sensory acquisition to multiscale maps and navigation. Nat. Rev. Neurosci 16, 94-108 (2015). [PubMed: 25601780]

141. Moser EI, Moser MB \& McNaughton BL Spatial representation in the hippocampal formation: a history. Nat. Neurosci 20, 1448-1464 (2017). [PubMed: 29073644]

142. Hardcastle K, Ganguli S \& Giocomo LM Cell types for our sense of location: where we are and where we are going. Nat. Neurosci 20, 1474-1482 (2017). [PubMed: 29073649]

143. Dai XC, Hong GS, Gao T \& Lieber CM Mesh Nanoelectronics: Seamless Integration of Electronics with Tissues. Acc. Chem. Res 51, 309-318 (2018). [PubMed: 29381054]

144. Tian BZ et al. Macroporous nanowire nanoelectronic scaffolds for synthetic tissues. Nat. Mater 11, 986-994 (2012). [PubMed: 22922448]

145. Scholvin J et al. Close-Packed Silicon Microelectrodes for Scalable Spatially Oversampled Neural Recording. IEEE transactions on bio-medical engineering 63, 120-130 (2016). [PubMed: 26699649]

146. Qing Q et al. Nanowire transistor arrays for mapping neural circuits in acute brain slices. Proc. Natl. Acad. Sci. USA 107, 1882-1887 (2010). [PubMed: 20133836]

147. Lacour SP, Courtine G \& Guck J Materials and technologies for soft implantable neuroprostheses. Nat. Rev. Mater 1, 16063 (2016).This review highlighted the importance of minimizing the physical and mechanical mismatch between neural tissues and implantable electrodes from a perspective of neuroprosthetics.

Nat Rev Neurosci. Author manuscript; available in PMC 2019 June 01. 
148. Lee H, Bellamkonda RV, Sun W \& Levenston ME Biomechanical analysis of silicon microelectrode-induced strain in the brain. J. Neural Eng 2, 81-89 (2005). [PubMed: 16317231]

149. Schwarz DA et al. Chronic, wireless recordings of large-scale brain activity in freely moving rhesus monkeys. Nat. Methods 11, 670-676 (2014). [PubMed: 24776634]

150. Rousche PJ et al. Flexible polyimide-based intracortical electrode arrays with bioactive capability. IEEE Trans. Biomed. Eng 48, 361-371 (2001). [PubMed: 11327505]

151. Minev IR et al. Electronic dura mater for long-term multimodal neural interfaces. Science 347 , 159-163 (2015). [PubMed: 25574019]

152. Tyler WJ OPINION The mechanobiology of brain function. Nat. Rev. Neurosci 13, 867-878 (2012). [PubMed: 23165263]

153. Polikov VS, Tresco PA \& Reichert WM Response of brain tissue to chronically implanted neural electrodes. J. Neurosci. Meth 148, 1-18 (2005).

154. Henze DA et al. Intracellular features predicted by extracellular recordings in the hippocampus in vivo. J Neurophysiol 84, 390-400 (2000). [PubMed: 10899213]

155. Schmitzer-Torbert N, Jackson J, Henze D, Harris K \& Redish AD Quantitative measures of cluster quality for use in extracellular recordings. Neuroscience 131, 1-11 (2005). [PubMed: 15680687]

156. Schmitzer-Torbert N \& Redish AD Neuronal activity in the rodent dorsal striatum in sequential navigation: separation of spatial and reward responses on the multiple T task. J. Neurophysiol 91, 2259-2272 (2004). [PubMed: 14736863]

157. Gray CM, Maldonado PE, Wilson M \& McNaughton B Tetrodes markedly improve the reliability and yield of multiple single-unit isolation from multi-unit recordings in cat striate cortex. J. Neurosci. Meth 63, 43-54 (1995).

158. Jog MS et al. Tetrode technology: advances in implantable hardware, neuroimaging, and data analysis techniques. J. Neurosci. Meth 117, 141-152 (2002).

159. Insanally $\mathrm{M}$ et al. A low-cost, multiplexed mu ECoG system for high-density recordings in freely moving rodents. J. Neural Eng 13, 026030 (2016). [PubMed: 26975462] 


\section{Box 1}

\section{Scaling of electrophysiological recording at the single-neuron level}

Since the advent of both transistor computers and microelectrode probes in the 1950s, the growth of computational power in computers and the number of neurons that can be monitored using electrode technologies have exhibited surprisingly similar trends in the past decades. The exponential growth of artificial computational power in computers is best approximated by Moore's Law, which states that the number of transistors per square inch of integrated circuits doubles every $~ 2$ years (fitted doubling time is 1.997 years; see panel a of the figure). Similarly, the number of simultaneously recorded neurons by implantable electrodes approximately doubles every 7 years, as first revealed by Stevenson and Kording in 2011 (fitted doubling time is 6.95 years; panel a) ${ }^{39}$.

The relatively slow pace in the development of neurotechnologies reflects a lack of similar economic drives and industrial support for semiconductor industry. Scaling of recorded single neurons falls short of Moore's Law for three other key reasons: the difficulty of increasing sampling volume without causing additional tissue damage; the difficulty of optimizing input/output (I/O) interfaces in terms of accessibility to multiplexed, external recording instruments, bandwidth and weight; and the difficulty of scaling electrode sizes to afford a higher density and sampling resolution.

First, the implantation of electrodes inevitably induces damage to the endogenous neural tissue. For non-porous electrodes, such as microwires and MEAs fabricated on silicon, the implantation entails permanent damage and the displacement or loss of a solid volume of neural tissue. Therefore, to increase the sampling volume and number of recorded single neurons without significant expansion of neural tissue damage, macroporous structure has been introduced into electrode design $81,85,86,143,144$.

Second, scaling of simultaneously recorded single neurons requires a substantial increase in the multiplexity of individually addressable channels, calling for high-yield, channelnumber-independent parallel electrical connection of multiple recording electrodes to interface with peripheral recording electronics. Besides yield and convenience of I/O connection, inter-channel crosstalk and overall footprint of the electrodes also become an important consideration, as higher multiplexity and density of recording channels lead to electrical crosstalk unless the footprint is increased proportionally.

Third, reducing the size of conventional metal electrodes is fundamentally limited by the bandwidth of electrical recording, as electrode impedance and thermal noise show unfavourable scaling with reduction in electrode size (panels b,c $)^{145}$. This limit calls for new device concepts, such as active nanowire FETs that can be scaled down to subcellular regimes without loss of measurement bandwidth and sensitivity ${ }^{67,68,74,146}$. The electrode surface area of nanowire FETs for neural recording has been reduced to $0.06 \mu^{2}$ (ref. 146) or even to point-like detectors ${ }^{74}$ for highly localized detection of fullbandwidth neural signals, offering substantial opportunity for size reduction that is not possible by increasing the specific capacitance of metallic passive electrodes ${ }^{58}$. 
These three key challenges should be considered in the design of novel electrode technologies to afford high-density and high-multiplexity neural probes, and to continue or even surpass the exponential growth of single-neuron recording.
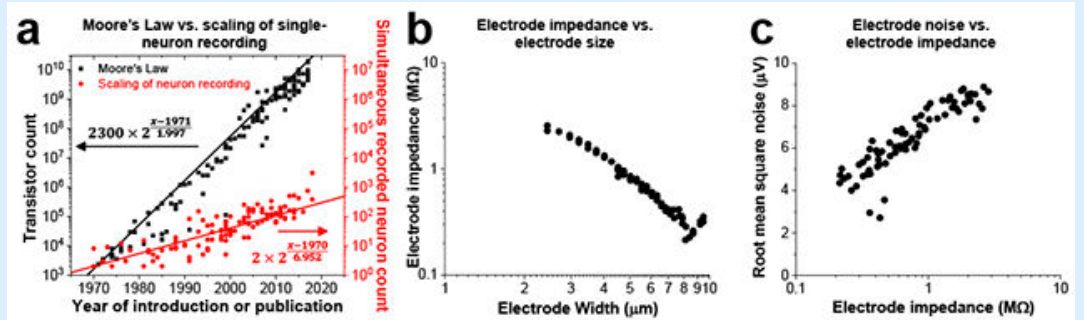


\section{Box 2 |}

\section{Mechanical properties of neural probes and neural tissue}

Neural recording electrodes must be placed near firing neurons to detect extracellular single-unit action potentials. Chronic brain implants exert constant force to the surrounding neural tissue, particularly during rapid accelerations and sudden halts of the implanted subject, if the rigidity of the implant materials is vastly different from that of the brain tissue.

Two physical quantities, Young's modulus [G] and bending stiffness [G], are usually used to describe rigidity, or the resistance to bend or deform (see Supplementary Box 1).

Although the Young's modulus defines a material's intrinsic mechanical properties, the bending stiffness of a specific neural probe plays a more direct role in determining the degree of mechanical mismatch and thereby the evoked chronic immune response in the neural tissue ${ }^{40,147}$.

Part a of the figure illustrates the range of Young's moduli of different materials relevant to conventional and more recent recording electrodes and neural tissue. Materials typically used for conventional neural recording electrodes, such as silicon, carbon and metal, are on average 8-9 orders of magnitude more rigid than brain tissue.

The effective bending stiffness values of conventional and emergent neural probes $^{81,87,97,148-151}$, along with that of a $20-100 \mu$ m thick slice of brain tissue ${ }^{152}$ are summarized in panel b. Conventional neural recording electrodes, such as the Michigantype silicon probe and microwire electrode, as well as more recent neural probes, such as the ultrasmall carbon ${ }^{90,97}$ polyimide ${ }^{150}$ and elastomer-based 'e-dura' probes ${ }^{151}$, are still orders of magnitude stiffer than the brain tissue. By taking advantage of the dependence of bending stiffness on probe thickness, mesh electronics is the only neural probe to date with effective bending stiffness comparable to that of neural tissue.

There are at least three unfavorable consequences of mechanical mismatch between the neural probe and the neural tissue. First, relative shear motion at the interface changes the relative position between recording electrodes and recorded neurons, leading to chronic instability of recordings. Second, a stiff implant causes repeated chronic damage to the much softer surrounding brain tissue, generating various chronic immune responses, including, most prominently, death and damage of neurons near the probe, and the proliferation of astrocytes and microglia to form a $\sim 100 \mu \mathrm{m}$-thick glial sheath that insulates the recording electrodes from neurons ${ }^{153}$. Third, as a result of the chronic immune response, the natural distribution of neurons and glial cells is considerably perturbed at the electrode-brain interface. As glial cells are cooperatively important in defining the functional evolution of neural networks ${ }^{42,43}$, this perturbation prevents the study of the activity of individual neurons and their encompassing neural circuits in their native state and environment. Therefore, a chronically stable electrode-brain interface should minimize shear motion and chronic immune response, and should avoid disturbing the natural distribution of neurons and other non-neuronal cells, by making tissue-like electronics using materials with similar mechanical properties to brain tissue (panel d). 
a Young's modulus of different materials

b Bending stiffness of different recording electrodes
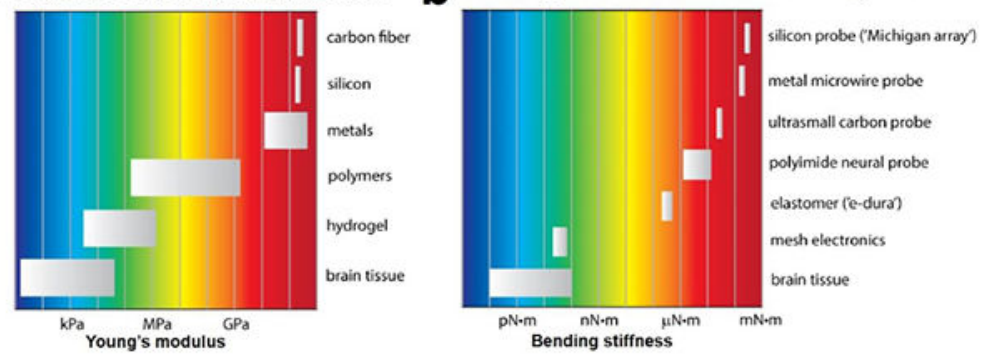

C

Neural probe - neural tissue interface neuron astrocyte microglia
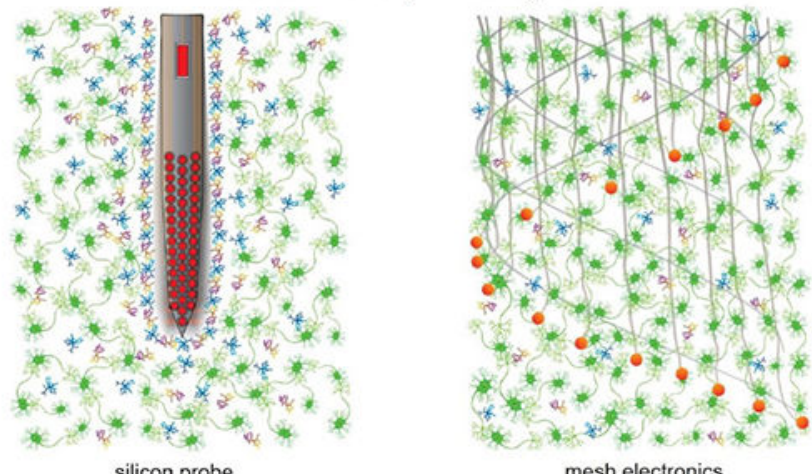

silicon probe

mesh electronics 


\section{Box 3 | \\ Challenges and strategies of tracking individual neurons with chronic recording}

An extracellular electrode can record single-unit spikes from multiple active neurons within the detectable distance of $\sim 140 \mu \mathrm{m}^{15}$. This fact imposes challenges of assigning the detected spikes to different neurons, and tracking the same neurons in chronic recordings.

Two properties of extracellular recording help overcome these challenges. First, action potentials have 1-2 ms durations and longer interspike intervals (ISIs), thus reducing signal overlap from different neurons in the time domain. Second, the extracellularlyrecorded spike amplitude and waveform depend on the distance and relative position of the electrode to the firing neuron ${ }^{20,154}$, thus enabling triangulation of neuron location by spatially oversampled multi-electrode recording $16,21,145$. Specific quantitative methods are summarized below.

\section{Spike amplitude}

The amplitude of an extracellularly recorded spike is a function of the distance of the electrode from the soma ${ }^{154}$. Therefore, neurons at different distances from the same electrode exhibit different spiking amplitudes, and the same neuron with constant distance from the electrode should exhibit a constant amplitude in chronic recording. This method has been used for assessment of chronic recording stability $58,61,79,97$.

\section{Spike waveform}

Neurons with different relative positions to the same electrode also exhibit different waveforms ${ }^{20}$, and the same neuron with constant relative position to an electrode should exhibit an unchanged waveform over time. Waveform analysis has been used in chronic in vivo electrophysiology studies to demonstrate recording stability ${ }^{87,88}$.

\section{Principal component analysis (PCA)}

Each recorded spike is a representation in $N$-dimensional space where $N$ is the total number of data points that comprise the spike. The dimensionality can be reduced by PCA to extract the greatest waveform variances between different neurons, to demonstrate chronic recording stability over short ${ }^{60,97}$ and long timescales ${ }^{83,88}$.

\section{Spike waveform auto- and cross-correlation}

Waveform autocorrelation is computed as the Pearson correlation coefficient for spikes belonging to the same neuron (similarity $\sim$ ), and cross-correlation to different neurons ( similarity <1) over time. This method was used to evaluate both short-term (several weeks) $)^{79}$ and long-term (several months to a year) ${ }^{83,103}$ chronic recording stability of single neurons.

\section{L-ratio analysis}

The L-ratio quantifies how well separated the spikes in each cluster are from other spikes in the $\mathrm{N}$-dimensional space ${ }^{155}$, with an L-ratio $<0.05$ considered good separation or 
isolation ${ }^{155,156}$. Consistently good separation of the same unit has been used to confirm correct assignments of single neurons ${ }^{103}$.

\section{Multisite detection of same action potentials}

Oversampled recordings of action potentials have advantages to cross-validate the presence of a firing neuron on multiple recording sites ${ }^{21,157,158}$. Moreover, a benefit of high-density oversampling electrodes ${ }^{145}$ is that small mechanical shifts between the electrode and the detected neuron can be partly compensated by electronically switching to adjacent electrodes 46 .

\section{ISI histogram and firing rate}

The intrinsic biophysical properties of neurons, such as ISI and firing rates that are readily attainable from sorted spike trains, have been used to assign spikes to individual neurons ${ }^{94}$. ISI histograms and firing rate analyses were used to demonstrate short-term (several weeks) ${ }^{60}$ and long-term (several months to a year) $83,88,103$ chronic stability of single-neuron recordings.

\section{Phase locking to theta oscillation}

The identity of individual neurons can also be revealed by their characteristic interactions with the encompassing neural circuit. In the hippocampus and parts of the cortex, one of such interactions is manifested as phase locking of single-unit firing events to the slowwave, theta oscillation in the $4-8 \mathrm{~Hz}$ range ${ }^{11}$. Phase locking has been used to confirm assignment and chronic interrogation of single-neuron activity 58,83 . 
Conventional Electrode Technologies
Recent Development in Electrode Technologies

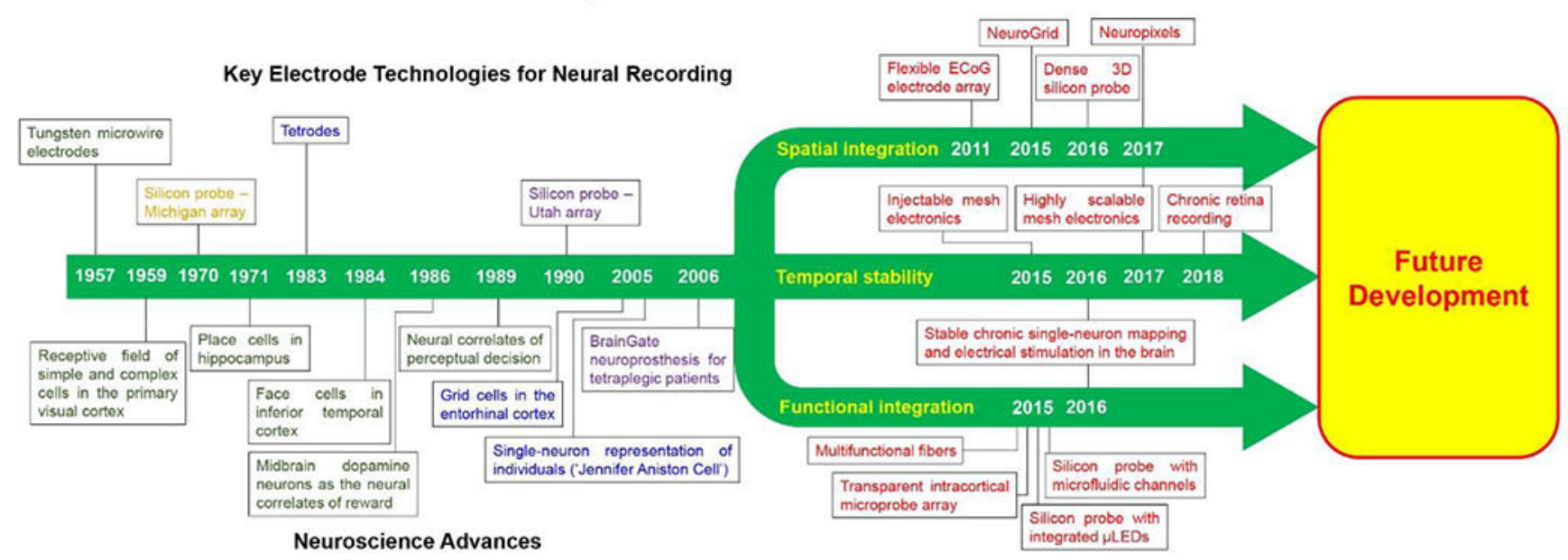

Fig. $1 \mid$. Neural recording electrode technologies.

On the left, conventional electrode technologies for in-vivo neural recordings are shown above the timeline, whereas key neuroscience discoveries and breakthroughs enabled by these technologies are shown below the timeline with the same colour coding as each corresponding electrode technology. On the right, recent development of neural recording electrode technologies is summarized in three categories for neural probes with high spatial integration, long-term temporal stability and multifunctional integration. Electrode technologies belonging to more than one category are connected with multiple lines. 


\section{a Basics of electrode technology for recording signals in neural tissue}

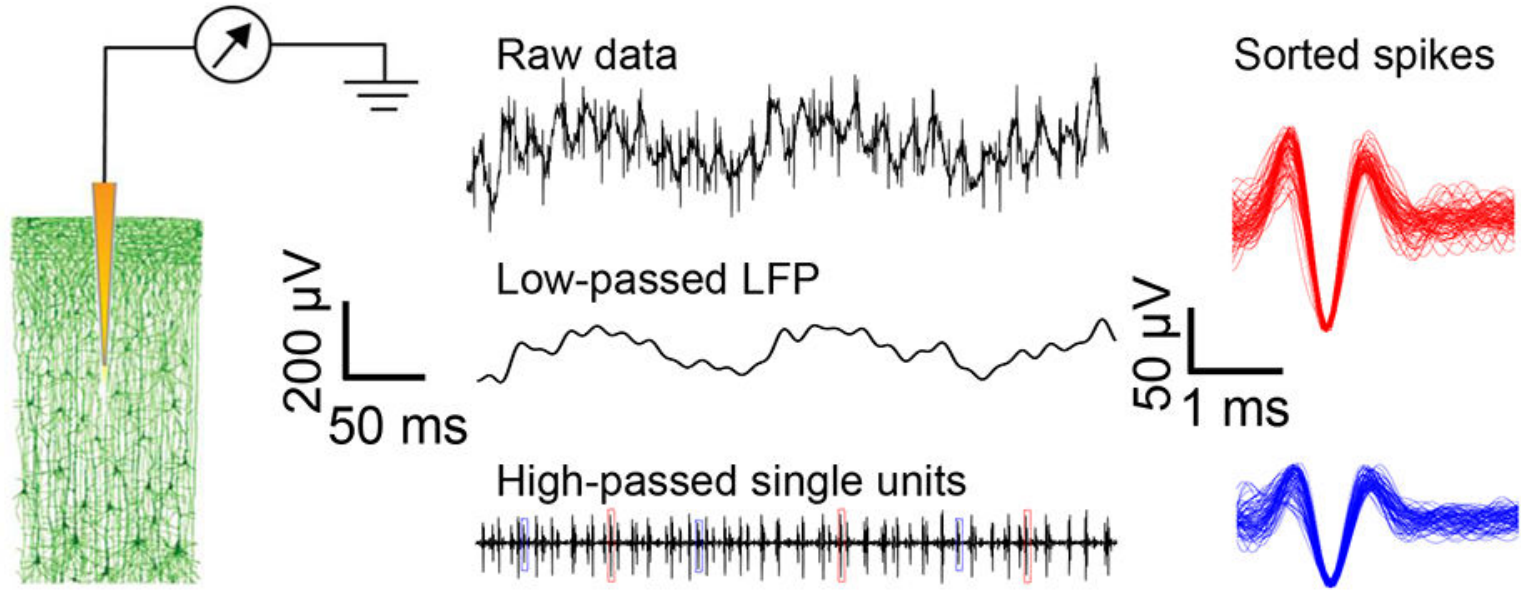

\section{b Spatiotemporal limitations of existing neurotechnologies}

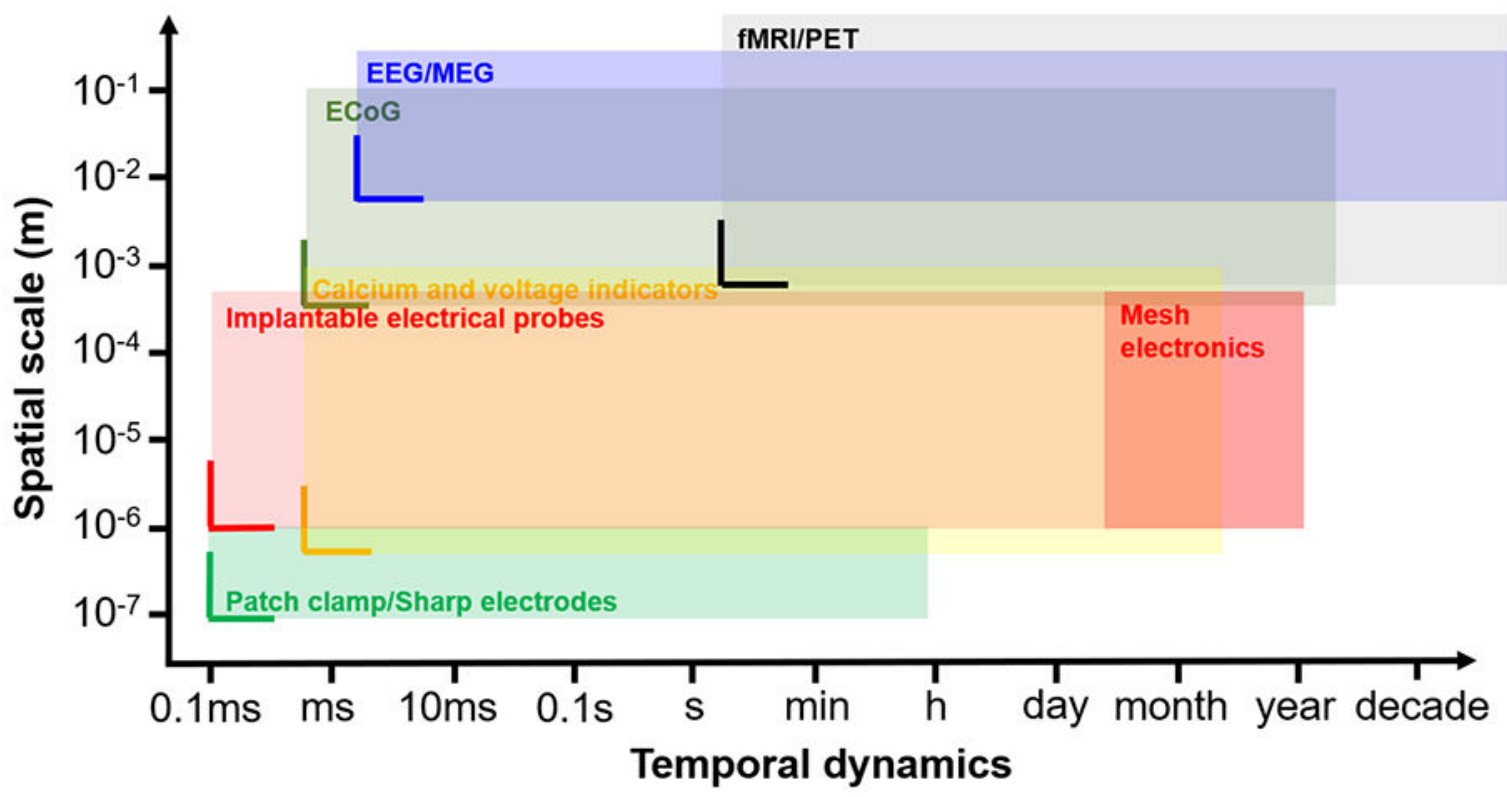

Fig. 2 |. Basic principles and physical constraints of electrode technologies.

a Schematic depicting the basic physical principles of measuring bioelectrical signals by recording electrodes in neural tissue, with representative raw, low-pass-filtered and highpass-filtered neural recording traces (middle) and sorted spikes (right) measured by an electrode. $\mathbf{b}$ | The essential physical constraints (in particular, the spatiotemporal dilemma) of various existing neurotechnologies (in particular, implantable electrical probes, the main focus of this Review) have encouraged advances in the field of neuroengineering. The horizontal and vertical solid lines represent resolution in temporal and spatial scale, 
respectively, whereas the extent of the rectangular shade represents the spatiotemporal span of each neurotechnology. 
a

High-density electrodes b

\section{Ultra-stable long- term recording electrodes}

C

\section{Multifunctional electrodes}
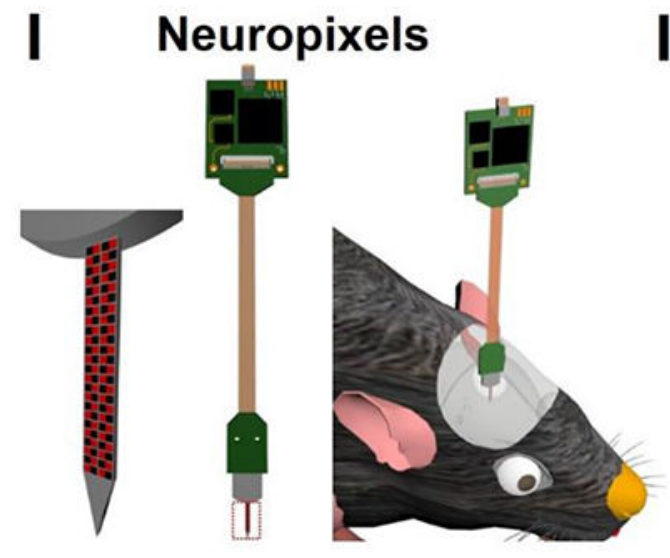

II

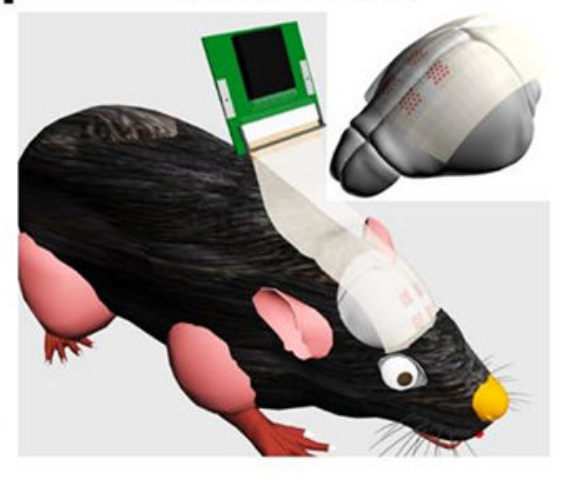

\section{Mesh Electronics}
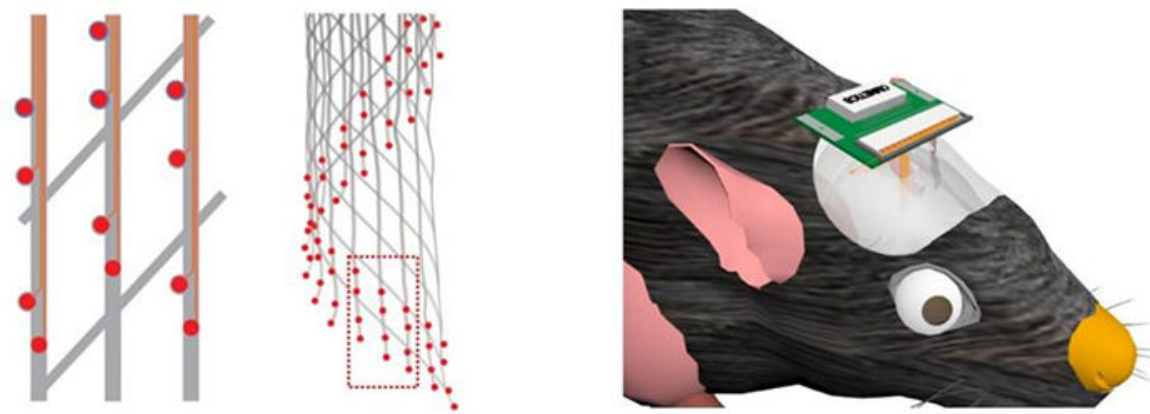

\section{| Multifunctional fiber || Multifunctional silicon probe}
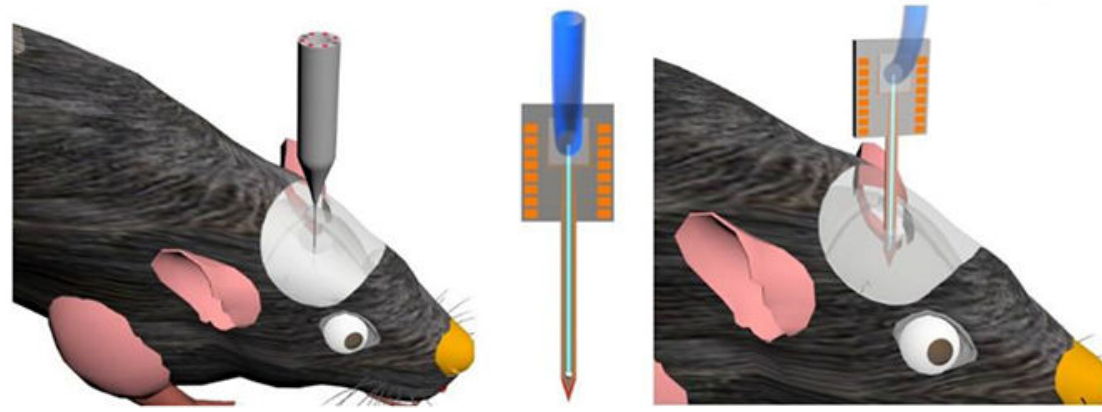

Fig. 3 |. Emerging neural recording electrode technologies.

Schematics of representative emergent neural recording electrodes in recent development, shown in three categories for high spatial integration (Neuropixels and NeuroGrid (a)), longterm temporal stability (mesh electronics (b)) and multifunctional integration (multifunctional fiber and silicon probes incorporating optical stimulation and fluidic delivery capabilities (c)). For each representative electrode technology, a schematic for the standalone probe showing the basic structure and that for the probe interface on a mouse head are both shown. A close-up view of the electrode region is also included for the red 
dashed box in $\mathbf{a}, \mathbf{I}$ and $\mathbf{b}$. The same colour coding is used for all schematics: red, electrodes; orange, interconnect wires and I/O bonding pads; grey, insulating layer. 
Table 1 |

Comparison of different properties of novel electrode technologies

\begin{tabular}{|c|c|c|c|c|c|c|}
\hline Electrode technology & Multiplexity & Stability & Immune response & Functionality & $\begin{array}{l}\text { Potential use in } \\
\text { neuroscience }\end{array}$ & Refs \\
\hline Neuropixels & 960 channels & $\begin{array}{l}\text { Up to } 60 \\
\text { days with } \\
\text { global SNR } \\
\text { and event } \\
\text { rates for } \\
\text { selected } \\
\text { channels }\end{array}$ & - & Recording only & $\begin{array}{l}\text { Recording from } \\
\text { multiple brain } \\
\text { regions } \\
\text { simultaneously to } \\
\text { provide insight on } \\
\text { the understanding } \\
\text { of the global } \\
\text { coordination of } \\
\text { brain activities }\end{array}$ & 49,52 \\
\hline 3D silicon probe & 1024 channels & $\begin{array}{l}\text { Viable for } \\
\text { chronic } \\
\text { studies but } \\
\text { not } \\
\text { evaluated }\end{array}$ & - & Recording only & $\begin{array}{l}\text { Understanding of } \\
\text { computations in } \\
\text { brain circuits } \\
\text { comprising } \\
\text { coordinated } \\
\text { activation of large } \\
\text { populations of } \\
\text { neurons distributed } \\
\text { across brain areas }\end{array}$ & 51 \\
\hline NeuroGrid & 120-256 channels & $\begin{array}{l}10 \text { days of } \\
\text { durable } \\
\text { single-unit } \\
\text { recordings }\end{array}$ & - & Recording only & $\begin{array}{l}\text { Large scale } \\
\text { monitoring of } \\
\text { neural activities in } \\
\text { the dorsal cortical } \\
\text { surface }\end{array}$ & 58,62 \\
\hline $\begin{array}{l}\text { Flexible multiplexed } \\
\text { electrode array }\end{array}$ & 360 channels & $\begin{array}{l}30 \text { days of } \\
\text { ECoG-type } \\
\text { signal } \\
\text { recording }\end{array}$ & - & Recording only & $\begin{array}{l}\text { Mapping of spatial } \\
\text { properties of } \\
\text { cortical activities } \\
\text { including seizures }\end{array}$ & 57,159 \\
\hline Polymer electrode array & 1024 channels & $\begin{array}{l}\text { An average } \\
\text { of } 20 \% \text { of } \\
\text { single units } \\
\text { can be } \\
\text { tracked up } \\
\text { to day } 10 ; \\
\text { without } \\
\text { rigorous } \\
\text { tracking, } \\
\text { detectable } \\
\text { number of } \\
\text { neurons on } \\
\text { day } 283 \text { is } \\
50 \% \text { the } \\
\text { maximum } \\
\text { number on } \\
\text { the same } \\
\text { shank }\end{array}$ & $\begin{array}{l}160 \text { days with } \\
\text { astrocyte } \\
\text { proliferation }\end{array}$ & Recording only & $\begin{array}{l}\text { Large-scale } \\
\text { mapping of fast } \\
\text { dynamics and } \\
\text { long-term } \\
\text { evolution of } \\
\text { anatomically } \\
\text { distributed neural } \\
\text { circuits }\end{array}$ & 55 \\
\hline Mesh electronics & 16-128 channels & $\begin{array}{l}\sim 1 \text { year } \\
\text { with single } \\
\text { neuron } \\
\text { tracking }\end{array}$ & $\begin{array}{l}\text { Up to } \sim 1 \text { year with } \\
\text { no chronic immune } \\
\text { response }\end{array}$ & $\begin{array}{l}\text { Recording and } \\
\text { electrical } \\
\text { stimulation }\end{array}$ & $\begin{array}{l}\text { Chronic studies of } \\
\text { learning and } \\
\text { memory, and } \\
\text { cognitive decline } \\
\text { during ageing on a } \\
\text { single-neuron basis }\end{array}$ & $81,83,84,87$ \\
\hline $\begin{array}{l}\text { Multifunctional flexible } \\
\text { polymer fibres }\end{array}$ & $\begin{array}{l}6 \text { electrodes, } 1 \\
\text { waveguide and } 2 \\
\text { fluidic channels }\end{array}$ & $\begin{array}{l}\text { Up to } 3 \\
\text { months } \\
\text { with single } \\
\text { neuron } \\
\text { tracking }\end{array}$ & $\begin{array}{l}\text { Up to } 3 \text { months } \\
\text { with limited } \\
\text { chronic immune } \\
\text { response }\end{array}$ & $\begin{array}{l}\text { Recording, } \\
\text { optical } \\
\text { stimulation and } \\
\text { microfluidic } \\
\text { delivery of } \\
\text { biologics }\end{array}$ & $\begin{array}{l}\text { Deconstruction of } \\
\text { neural circuits with } \\
\text { optogenetic and } \\
\text { pharmacogenetic } \\
\text { manipulations and } \\
\text { simultaneous } \\
\text { electrical } \\
\text { interrogation }\end{array}$ & $88,98,127$ \\
\hline
\end{tabular}

Nat Rev Neurosci. Author manuscript; available in PMC 2019 June 01. 


\begin{tabular}{|c|c|c|c|c|c|c|}
\hline Electrode technology & Multiplexity & Stability & Immune response & Functionality & $\begin{array}{l}\text { Potential use in } \\
\text { neuroscience }\end{array}$ & Refs \\
\hline $\begin{array}{l}\text { Transparent } \\
\text { intracortical micro- } \\
\text { optoelectrode array }\end{array}$ & 16 optoelectrodes & Acute & - & $\begin{array}{l}\text { Recording and } \\
\text { optical } \\
\text { stimulation }\end{array}$ & $\begin{array}{l}\text { Dissection of } \\
\text { spatially and } \\
\text { temporally specific } \\
\text { neural population } \\
\text { maps and } \\
\text { associated neural } \\
\text { codes by tailored } \\
\text { and feedback- } \\
\text { controlled } \\
\text { stimulation }\end{array}$ & 130 \\
\hline $\begin{array}{l}\text { Silicon probe with } \\
\text { integrated microLEDs }\end{array}$ & $\begin{array}{l}32 \text { recording } \\
\text { electrodes and } 12 \\
\text { microLEDs }\end{array}$ & $\begin{array}{l}\text { Viable for } \\
\text { chronic } \\
\text { studies but } \\
\text { not } \\
\text { evaluated }\end{array}$ & - & $\begin{array}{l}\text { Recording and } \\
\text { optical } \\
\text { stimulation }\end{array}$ & $\begin{array}{l}\text { Cellular-level } \\
\text { circuit control and } \\
\text { analysis in deep- } \\
\text { brain structures }\end{array}$ & 122 \\
\hline $\begin{array}{l}\text { Silicon probe with } \\
\text { microfluidic channels }\end{array}$ & $\begin{array}{l}8 \text { or } 16 \text { recording } \\
\text { electrodes and up } \\
\text { to } 3 \text { independent } \\
\text { chemical inlets }\end{array}$ & Acute & - & $\begin{array}{l}\text { Recording and } \\
\text { microfluidic } \\
\text { delivery of } \\
\text { biologies }\end{array}$ & $\begin{array}{l}\text { Elucidation of } \\
\text { brain circuitry } \\
\text { activity and } \\
\text { functions by } \\
\text { pharmacological } \\
\text { modulations }\end{array}$ & 131,132 \\
\hline
\end{tabular}

'-', not evaluated; ECoG, electrocorticography; LED, light-emitting diode; SNR, signal-to-noise ratio. 